\title{
Portugal y su imperio frente a la descolonización 1945-62
}

\author{
Adolfo Cueto \\ Doctorando. Departamento Historia Contemporánea. UNED
}

Portugal and her empire face the descolonization 1945-1962

\begin{abstract}
RESUMEN
Portugal logró construir un imperio colonial en Africa tan notable como desajustado a las aparentes capacidades del país, y eso

fue gracias a una difícil combinación de factores endógenos y exógenos, un éxito que llevó a que los dirigentes lusos confiriesen al Ultramar un papel ideológico capital. Sin embargo, tras la Segunda Guerra Mundial los factores externos que habían favorecido la materialización del Imperio desaparecen, $y$ en este nuevo contexto marcado por la Guerra Fría y la ola descolonizadora, Portugal es incapaz de contemporizar sus relaciones con las colonias. El temor a que la pérdida de los territorios extraeuropeos acabase también con el Régimen, además de otros factores, determinó la imposibilidad de que el Gobierno aceptase revisar sustancialmente su política inmovilista, obligándose a sostenerla en circunstancias internacionales $y$ nacionales extremadamente difíciles, especialmente a partir de 1961. A pesar de la evidente imposibilidad de mantener la soberanía en Ultramar por la fuerza en ese contexto, para buena parte de la cúpula del Estado Novo cualquier alternativa que pusiese en cuestión la «unidad pluricontinental de Portugal y sus provincias ultramarinas» era inaceptable,

al ser la piedra angular que sostenía el mito del "caso único» del colonialismo portugués y por consiguiente la justificación de su continuidad, siendo
\end{abstract}

\section{ABSTRACT}

Portugal managed to build a colonial empire in Africa which was as remarkable as out of proportion with the country's limited resources. This was posible thanks to an odd combination of internal and external factors. This successful combination led Portuguese rulers to attach a great ideological meaning to the country's overseas possessions.

Alter WWII, however, the external factors favouring Portuguese colonial expansion disappear. In the new context of the Cold War and Decolonization, Portugal seems unable to reach a successful compromise with her colonies. Fears arise that the loss of overseas territories might as well finish with the Salazar Régime. Along with other causes, these fears made it impossible for the Portuguese government to change its rigid policy, which was kept despite difficult national and international circumstances, especially since 1961.

Notwithstanding this context, most of the Estado Novo Establishment refused to contemplate any other alternative which might question «the multi-continental unity of Portugal and her overseas provinces». This "unity" was the foundation of the myth of the "unique case» of Portuguese colonialism. The dogmatic character of such unity, together with the dictatorial nature of the régime, prevented any open discussion about the issue.

For all these reasons, the only way out of this impasse was war, alongside some 
además el dogma que impedía una discusión interior abierta y perniciosa sobre el futuro de las colonias obviamente junto a la propia naturaleza antidemocrática del Régimen. Por esa razón, el único camino posible era el de la guerra, complementada con algunas reformas administrativas, económicas y sociales que ejecutaría Adriano Moreira, y que no pudieron ser otra cosa que una certificación de los estrechos límites en los que el Portugal de Salazar podía moverse.

PALABRAS CLAVE: Política colonial portuguesa. Guerra colonial. Portugal y la descolonización. administrative, economic and social reforms. These reforms were implemented by Adriano Moreira, but they were the confirmation of the narrow margin of manoeuvre of Salazar's Portugal.
KEYWORDS:
Colonial Portuguese policy. Colonial war.
Portugal and decolonization.

El Régimen de Salazar sobrevivió a la Segunda Guerra Mundial haciendo un alarde de equilibrio diplomático entre las presiones de los Aliados y del Eje, que en ambos casos pretendieron revisar la neutralidad lusa a su favor. Con la victoria total de los primeros, el futuro de los regímenes autoritarios ibéricos podía parecer incierto, pero en el caso del más pequeño de los hermanos peninsulares, ese extremo no podía estar más alejado de la realidad: la actitud colaboracionista del Estado Novo en los últimos compases de la contienda, la apuesta británica por la continuidad de A. de Oliveira Salazar al frente del país como garantía de estabilidad, y el valor geoestratégico del rectángulo portugués y de sus islas adyacentes en el naciente mundo bipolar, le valieron a Portugal un engarce internacional sino completo, ya que no fue invitado a figurar como miembro fundador de las Naciones Unidas, al menos sí cómodo, tal y como atestigua el que se pudiese beneficiar de la ayuda del Plan Marshall o su participación en la OTAN desde su creación en 1949¹. En definitiva, a lo que sí se asistió fue a una revalorización del activo luso, que se vio también auxiliada por el limbo internacional en el que quedó desde 1945 el otro componente de la dualidad ibérica, la España de Franco².

De nuevo Portugal salía airoso de una conflagración mundial, esta vez gracias a un juego de resistencias y concesiones osado que le garantizó la salvación del Régimen y el mantenimiento de su integridad territorial metropolitana y colonial, los

1 Para un mayor conocimiento de la inserción portuguesa en el Bloque Occidental en los últimos años de la Guerra y hasta el final de la década de los cuarenta, ver: CASTAÑO, David: Paternalismo e Cumplicidade: As relações Luso-Britânicas de 1943 a 1949. Lisboa, Colecção Prémio Teixeira de SampaioAssociação dos Amigos do Arquivo Histórico Diplomático, 2006.

2 Para la inserción de la Península lbérica en el sistema internacional contemporáneo ver: TELO, Antonio y TORRE GÓMEZ, Hipólito: Portugal y España en los sistemas internacionales contemporáneos. Mérida, Junta de Extremadura, 2003; JIMÉNEZ REDONDO J. C.: Franco e Salazar: as relações luso-espanholas durante a Guerra Fría (1930-55). Lisboa, Assirio e Alvim, 1996; JIMÉNEZ REDONDO, J. C.: Pervivencia y superación del Iberismo: los nuevos condicionantes de la política peninsular (1939-55). Madrid, Servicio de Publicaciones de la Universidad Complutense de Madrid, 1992. 
dos objetivos básicos perseguidos por las autoridades estadonovistas, tal y como antes que ellas ya se habían propuesto defender las republicanas en la conflagración de 1914. Sin embargo, desde 1945 a la perpetuación del régimen «viejo» portugués se contraponía un orden internacional nuevo, y en él, el papel que cabía a los estados europeos suponía su relegación al rango de actores secundarios y dependientes de la protección de una de las dos superpotencias mundiales, mientras Europa se convertía en el epicentro del choque de bloques en el juego de la Guerra Fría.

En conclusión, y en términos meramente continentales, la nueva situación mundial favorecía la inserción en el bloque Occidental de Portugal, pero la línea de fractura que representó el Telón de Acero no tardó en afectar también al resto de los continentes, y es en ese ámbito «global» donde empiezan a surgir los problemas para el país ibérico.

En el nuevo contexto internacional ese viejo régimen seguirá con interés y temor el despertar de los pueblos colonizados de Asia y África y sus luchas por la emancipación, un proceso trascendente para el mundo y preocupante para él, sobre el que la bipolaridad ejercerá una influencia desmoralizante para Lisboa.

Sin embargo, no por ello una de las máxima del salazarismo dejará de serlo, la de mantener incólume el "patrimonio colonial portugués». Es por eso que este asunto, la defensa de su soberanía sobre las colonias, absorberá buena parte de los esfuerzos que el Gobierno Portugués iba a realizar en delante de cara al mundo, confiando en que la batalla por la descolonización se librase en los foros internacionales y en el marco de las relaciones bilaterales, deseo que se cumple parcialmente hasta el estallido en marzo de 1961 de la guerra en Angola, instante desde el que a la cruzada diplomática lusa hay que sumarle una nueva dimensión para definir correctamente los contornos de su problema colonial, la del conflicto armado.

\section{DESCOLONIZAR O RESISTIR. EL FALSO DILEMA DE PORTUGAL}

Decimos falso dilema ya que en ningún momento las autoridades salazaristas plantearon la descolonización como una opción para su «problema ultramarino», salvo para concebirla en un plazo «secular», y esto a pesar de la existencia de diferentes pareceres en cuanto al itinerario a seguir y el destino de la política colonial dentro del propio Estado Novo. Por tanto, el mantenimiento del Imperio era un principio fundamental para el que además contaba con un respaldo popular casi unánime. Más aun, la mayor parte de la oposición democrática compartió este planteamiento durante mucho tiempo, al no barajar tampoco como posible ni una autodeterminación inmediata, ni tampoco la celebración de un referéndum en el que la alternativa a la integración en Portugal solo fuese la independencia total. Si acaso, y de forma individual, algunos opositores defendieron la posibilidad de 
una consulta de autodeterminación tras un plazo de «elevación cultural» de los nativos, algo que consideraban imprescindible para que pudiesen ejercer ese derecho político de manera efectiva, pero sin especificar tampoco el tiempo necesario para que esa capacitación se alcanzase ${ }^{3}$. Únicamente el Movimento de Unidade Democrática Juvenil en 1953 y el Partido Comunista Português desde 1957 se declararon favorables al reconocimiento del derecho a la autodeterminación y a la emancipación de las colonias,

De ahí que la disyuntiva no era tanto descolonizar o resistir, cuanto la dirección en la que caminar para replantear la relación Metrópoli-Colonias en un mundo hostil, debatiéndose entre un abanico de posibilidades que iban de la asimilación defendida por el núcleo duro del Régimen, hasta la federación más o menos compartida en lo general por el ala más evolucionista del Estado Novo y por el oposicionismo democrático, pasando por supuesto por los diferentes grados de un sistema autonómico.

De todas maneras, y dado el clima general de rechazo al colonialismo, resulta difícil de explicar el porqué de esa actitud portuguesa de oposición frontal a la descolonización, particularmente desde el inicio de la década de los sesenta. No obstante, la observación de algunos aspectos generales puede ayudar a su esclarecimiento parcial, y eso es lo que intentaremos hacer a continuación.

Antes del estallido de la Segunda Guerra Mundial se podría decir que el «valor» del Tercer Imperio Portugués se desviaba parcialmente de los términos económicos y geoestratégicos convencionales que justificaban la dominación, o por lo menos cabría observar que la «lógica de explotación capitalista» de los recursos ultramarinos no se había implantado totalmente — para lo que habría que esperar a etapas posteriores, ya en plena hoguera descolonizadora ${ }^{4}$.

De hecho, la concreción del Imperio Portugués se había fundamentado en cuatro axiomas interrelacionados y coincidentes en el tiempo, siendo algunos específicos del caso luso: el primero, una voluntad colonizadora sustentada en la concepción prospectiva que suponía que de la ocupación de tierras africanas podrían obtenerse grandes beneficios para el desarrollo de la Metrópoli; en segundo lugar, el equilibrio de poderes del Viejo Continente y mundial que permitió que una pe-

${ }^{3}$ GALVÃO, Henrique: Colonialismo, anticolonialismo, autodeterminación. Rio de Janeiro, GERMINAL, 1961.

${ }^{4}$ En relación a este punto, existe una interesante controversia historiográfica en cuanto al carácter económico o no del Imperio en estas primeras décadas. Mientras algunos historiadores extranjeros como Hammond llegaron a calificar el Tercer Imperio Portugués como «anti-económico», historiadores portugueses matizan esa percepción señalando que a pesar de los costes que para el Estado supusieron las campañas de ocupación, existen otros factores económicos indirectos y otros no cuantificables que contradicen esa teoría antieconomicista. Si hacemos caso a lo que nos dice A. Telo, una de los beneficios más importantes del Imperio para Portugal era el ed aportar un importantísimo flujo de divisas extranjeras a un Estado con grande dificultades para adquirirlas entonces. Ver: TELO, Antonio y TORRE GOMEZ, Hipólito: Portugal y España en los sistemas internacionales contemporáneos. Mérida, Junta de Extremadura, 2003, pp. 81-89, y ALEXANDRE, Valentim: Velho Brasil, novas Áfricas. Portugal e o Imperio (1808-1975). Biblioteca das Ciencias do Homem, Edições Afrontamento, Porto, 2000, pp. 121-137. 
queña nación periférica lograse controlar una extensión territorial extra-europea de dimensiones sobresalientes; en tercer lugar, la revolución tecnológica de finales del siglo XIX, que había alterado totalmente el equilibrio de poder existente hasta entonces entre la resistencia de las tribus nativas, los accidentes geográficos y las dolencias del interior africano, y el afán expansionista del hombre blanco, inversión de fuerzas de la que incluso un Estado raquítico como el portugués se pudo beneficiar gracias a la importación «capacitacional» dificultosa y tardía de estos adelantos $^{5}$; y para terminar, un cuarto de naturaleza netamente ideológica y que complementa el primero, que determinó que ni la falta de rentabilidad imperial en los primeros lustros fuese impedimento para que el papel del Ultramar en las doctrinas de las diferentes sensibilidades políticas se fuese reforzando, hasta el punto de ser asumido como precipitado definitorio y capital de la identidad nacional portuguesa, y más aun para el régimen de Salazar que cultivó con ahínco durante la década de los treinta una mística imperial que asociaba íntimamente Nación con Imperio, e Imperio con herencia patrimonial sagrada e irrenunciable ${ }^{6}$.

Sin embargo, contrariamente a lo que había sucedido durante esas primeras décadas de construcción imperial, a partir de 1945 los factores que la habían posibilitado habían mutando o lo estaban haciendo. Por eso, contemplando el estado en el que se encuentran entre 1945 y 1961 esas circunstancias que antaño habían propiciado la corporeización del Imperio Portugués, se llega a comprender mejor la actitud inmovilista del Régimen ante la descolonización por una parte, y las dificultades con las que se habría de enfrentar por la otra.

En lo que se refiere a los factores de índole interna, cabe decir que permanecieron y permanecerían por bastantes años imperturbables en términos generales, viéndose incluso reforzados. El compromiso de la práctica totalidad de las fuerzas políticas del país con el mantenimiento del Ultramar perduró, pero a esto hay que sumar una novedad importante: tras el fin de la Guerra y de forma progresiva gracias en parte a la seguridad que dio esa determinación política de quedarse-, el Imperio empieza a ser «rentable» para la Metrópoli.

Las colonias en su conjunto se convirtieron en el primer socio comercial de Portugal con el discurrir de los años cincuenta ${ }^{7}$; lentamente fueron acogiendo en sus dura tierras a los inmigrantes metropolitanos que se asientan en las principales ciudades ultramarinas y en algunos establecimientos agrícolas del interior proyectados por los poderes públicos 8 ; y se tornaron progresivamente espacios abier-

5 TELO, Antonio: Economía e Imperio no Portugal Contemporâneo. Lisboa, Edições Cosmos, 1994, pp. 131-195.

${ }^{6}$ Para comprender los detalles de la situación ultramarina portuguesa en el contexto de las relaciones internacionales, vid.: TORRE GÓMEZ, Hipólito: «Las colonias portuguesas en la política internacional». En TORRE GÓMEZ, Hipólito de la: Portugal, España y África en los últimos cien años. IV Jornadas de estudios Luso-Españoles. UNED, Mérida, 1992, pp. 285 y ss.

7 ROSAS, Fernando (coord.): «Historia de Portugal: O Estado Novo». En: MATOSSO, José (dir.): Historia de Portugal, 8 vols. Círculo de Leitores, 1994, vol. 7, pp. 475 y 477.

8 Para un mayor conocimiento del proceso de colonización con poblaciones metropolitanas del Imperio Portugués, se puede consultar: CASTELO, Caudia Orvalho: Passagens para a África portuguesa: 
tos a las inversiones de los capitalistas portugueses gracias al repliegue de los capitales extranjeros por la Guerra, a las políticas de nacionalización de algunas compañías controladas por inversores foráneos y a la matización de la política de «condicionamiento industrial» que impedía que en las colonias se abriesen industrias. De esta forma, para los años sesenta en las colonias ya estaban presentes la mayor parte de los principales grupos empresariales metropolitanos, sin olvidar tampoco a otros pequeños y medianos emprendedores portugueses ocupados en la agricultura, el comercio y los servicios.

Hasta aquí, en términos meramente «internos», nada, excepto embrionarias organizaciones de nativos que apuntan hacia la gestación de movimientos de emancipación, perturbaba la solidez del dominio luso en Ultramar, por el contrario, tendía a justificarse más. Sin embargo, esta aproximación del Imperio luso a lo que la teoría política define como "colonización» encerraba un efecto que tenemos que observar también a la hora de valorar el porqué del inmovilismo portugués.

La cerrazón de mantenerse en Ultramar que había favorecido la concreción tardía de dos de los objetivos tradicionales del colonialismo: la explotación de los recursos coloniales en beneficio de la metrópoli, y el asentamiento de excedentes poblacionales, se irá convirtiendo a medida que avanzan los años cincuenta y sesenta en una hipoteca para el Estado Novo, al llevar implícita en su relativo y progresivo éxito la imposibilidad de revisar su política colonial sin grandes costes económicos, políticos y humanos, mayores cada año que pasaba. El camino seguido desde Lisboa con su desafío a los «vientos de la historia» fue reduciendo de manera paulatina el campo de maniobra político del propio Régimen al inhabilitar cualquiera de las alternativas encaminadas a diluir el dominio directo portugués, quedando por supuesto vedada la opción de la independencia. Lo que podría ser recomendable en caso de necesidad extrema, es decir, una revisión sustancial de la actitud inmovilista, tendría que hacerse necesariamente sacrificando: los intereses del capital nacional - tan próximo al poder e incapaz de pasar a un estadio neocolonial sin la protección directa de Portugal; el futuro de una nutrida comunidad de colonos - esto último siempre y cuando no se optase por favorecer a largo plazo una independencia blanca; la propia credibilidad política del Estado Novo ante sus principales apoyos sociales y económicos, con lo que se pondría en solfa la propia supervivencia del Régimen; e incluso para algunos sectores nacionalistas radicales, la emancipación del Imperio supondría renunciar a una parte capital de la identidad nacional portuguesa, abocando la idea de Portugal a la extinción tal y como se había concebido hasta entonces, y peor aun, para ellos podría poner en riesgo hasta la continuidad del país como Estado independiente en la Península Ibérica.

o povoamento de Angola e Moçambique com naturais da metrópole (1920-1974). Oporto: Edições Afrontamento, 2007. 
Lo dicho arroja algo de luz sobre el porqué del compromiso colonialista del Estado Novo, pero sin esclarecer totalmente las razones por las que se llegó a los extremos a los que se llegaría en esa defensa. No obstante, en esta primera toma e contacto con el problema colonial portugués, el esbozo no estaría completo sin la consideración de la otra cara de la moneda, la representada por el contexto internacional, y en este ámbito, aquél orden que había permitido que se crease el Imperio había desaparecido. Con todo, la conservación de las posesiones lusas seguía dependiendo del juego de fuerzas mundial tanto o más que en el pasado.

El diferencial táctico y técnico que en términos militares había posibilitado la ocupación de territorios extra-europeos por la fuerza desde el último cuarto del siglo XIX, se había vuelto a equilibrar.

Gracias a la occidentalización de una parte de las élites nativas, los pueblos asiáticos y africanos fueron generando movimientos de liberación y éstos estimulando las conciencias nacionales, y bajo la dirección de estas organizaciones independentistas las masas se encaminaron hacia la expulsión de los poderes coloniales. Este hecho llevó en el caso de África, a que hasta cierto punto se pudiesen atenuar las antiguas divisiones clánicas, presentando los nuevos conflictos contornos que superaban las hasta entonces normales rebeliones tribales, para plantearse como pretendidas luchas de liberación nacional. Pero no sólo las poblaciones sujetas a un mismo poder colonial tendieron a unirse contra éste, también se fue generando una solidaridad entre los pueblos colonizados que les llevaría a apoyarse los unos a los otros frente a los colonizadores, circunstancia diametralmente opuesta a la vivida en el otro periodo crítico de las relaciones potencias europeas-pueblos africanos, asiáticos y oceánicos, el de conquista, en el que éstos últimos carecían de unidad y obviamente de la solidaridad de otros.

Bien diferente también a aquel orden internacional multipolar que rigió el tránsito de siglo XIX al XX fue la Guerra Fría. La lucha Este-Oeste por ampliar las áreas de influencia y socavar el poder del rival contribuirá aun más a reequilibrar las fuerzas entre colonizados y colonizadores. La implicación progresiva de las dos superpotencias en los conflictos coloniales ayudó a los movimientos de liberación a defender sus reivindicaciones políticas frente a los "administradores», y en su caso, a sostener guerras asimétricas basadas en el recurso a la lucha guerrillera y a la subversión. Para esto último era fundamental el suministro de armamento moderno y adecuado, el adiestramiento y el apoyo táctico, técnico y logístico, y en ese terreno los principales «abastecedores» de los movimientos de liberación serían los países afro-asiáticos ya emancipados, que actuaron como intermediarios, y la URSS y sus satélites como fabricantes y tácticos.

Tal y como Portugal pudo ir comprendiendo por el seguimiento de este tipo de conflictos en colonias de otros poderes imperiales, afrontar una confrontación 
de esa naturaleza limitaba mucho las ventajas ofrecidas por las capacidades militares convencionales de los ejércitos regulares, y obligaba a los poderes establecidos a soportar unos costes elevados por el tipo de combate que se planteó y el dispositivo defensivo que requería, muy caro y que había de mantenerse durante todo el periodo que durase el conflicto, de lo que se desprendía que las posibilidades de resistencia de los colonizadores se reducían drásticamente en el caso de tener que recurrir a la fuerza para mantener su soberanía en las colonias. Y en el caso de Portugal este extremo no sólo encerraba los riesgos antedichos, sino que además implicaba el incremento de su dependencia del exterior, puesto que precisaba como los movimientos de liberación del apoyo económico, material y técnico de otros Estados para adaptar sus capacidades defensivas y ofensivas a las exigencias de la guerra que previsiblemente le impondría el enemigo, precisamente en un tiempo en el que su resistencia a descolonizar generaba un gran rechazo internacional, incluso entre sus aliados occidentales.

Por tanto, las esperanzas del Gobierno Portugués a comienzos de la década de los cincuenta pasaban necesariamente por confiar en que los movimientos de liberación tardasen en dar muestras de madurez en sus colonias, y cuando esto sucediese en su represión. Pero el grado de desarrollo de esos movimientos estaba sujeto también a circunstancias de carácter internacional relativamente alejadas de la capacidad de intercesión de Portugal.

Por un lado, dependía de la posición que los EEUU adoptase de cara a la descolonización, lo que se deduciría de su interpretación de las posibilidades y los riesgos que las emancipaciones suponían para la lucha de bloques y para el equilibrio que precisaba en su hemisferio entre los intereses de los aliados colonizadores y el deseo de atraerse a las nuevas naciones ávidas de independencia; y por el otro, de la capacidad de resistencia del «frente de los colonialistas» - si es que se puede hablar de tal unidad más allá de las iniciales connivencias que ofrecen en los foros mundiales ante la perspectiva del despojo-, condicionada a su vez por la actitud permisiva o no de Washington.

El compendio de todo lo dicho y su evolución determinó en cada momento el nivel de resistencia hasta el que Lisboa hubo de llegar para seguir presente en tres continentes, y paralelamente, también fue estableciendo el grado de virulencia con el que la comunidad internacional abordaba el «caso portugués» y por tanto el tiempo con el que Lisboa podría contar antes de que el fenómeno de las liberaciones se extendiese hasta las inmediaciones de sus posesiones, haciéndose el contagio en el caso extremo de llegar al contacto fronterizo imposible de evitar y la resistencia difícil de sostener. Y ese último escenario nefasto empezó temprano a tomar cuerpo, apenas una década después de que Portugal implementase sus primeras medidas inmovilistas. 


\section{EL IMPERIO PORTUGUÉS ANTE EL COLAPSO DE LOS IMPERIOS EUROPEOS}

La Segunda Guerra Mundial cercenó el poderío europeo y su capacidad de oposición, abriendo la puerta al éxito de las reivindicaciones de los colonizados, y plegó las voluntades de los imperialistas a las directrices de Washington como cabeza visible del bloque occidental. Así, el resultado no podía ser otro que un proceso de descolonización casi tan acelerado y general como el de colonización, a pesar de las renuencias iniciales de todos los poseedores y de las resistencias empecinadas de algunos gobiernos europeos.

Inmediatamente después de terminada la Guerra, el Gobierno Británico optó — no sin ciertas dudas - por conceder la independencia a sus colonias más maduras y con ellos por salvaguardar al menos unas relaciones especiales en el marco de la Mancomunidad Británica de Naciones con ellas. Otros poderes coloniales europeos que optaron por el recurso extremo a la fuerza, como fueron los casos de Holanda en Insulindia y de Francia en Indochina y Argelia demostraron su total ineficacia, saldándose con derrotas. Por tanto, a finales de la década de los cincuenta la resistencia a descolonizar de los grandes imperios europeos era inexistente en Asia; se deshacía con celeridad en el Norte de África -Francia estaba a punto de capitular en Argelia y España se acantonaba en el Sáhara Español y resistía a duras penas en Ifni; y estaba siendo seriamente cuestionada en el África Negra, donde los únicos que junto a Portugal no barajaban aun la alternativa de la autodeterminación a ningún plazo eran otras dos potencias menores: España y la Unión Sudafricana9 ${ }^{9}$.

A lo largo de estos años el movimiento anticolonialista no dejó de tomar cuerpo y fuerza. Hitos cronológicos como: la independencia de la India en 1947; la derrota francesa en Dien Bien Phu en 1954; la Conferencia de Bandung en 1955, de la que nace el No Alineamiento y el compromiso de todos los nuevos estados con la extinción total del colonialismo en el mundo; la intervención fallida de franceses, británicos e israelíes en Suez en 1956; las primeras independencias de colonias negras: Ghana en 1957 y Guinea-Conakry un año después; la Conferencia de Accra en 1958, donde las naciones africanas se comprometen con «el término de la presencia europea en el Continente»; y finalmente 1960, año en el que nacen dieciséis nuevos estados independientes en el África subsaharianos, son todos indicadores claros de que la «Era de los Imperios» tocaba su fin.

La URSS estuvo desde el principio del lado de los colonizados, con cuya actitud poco tenía que perder y mucho que ganar frente al bloque capitalista; y los EEUU, si bien es cierto que los gobiernos de H. Truman y de D. Eisenhower mo-

9 Para un mayor conocimiento sobre el proceso de descolonización, ver: CHAMBERLAIN, M. E.: La descolonización. La caída de los imperios europeos. Barcelona: Ariel Historia, 1997. GRIMAL, Henri: Historia de las descolonizaciones del siglo XX. Madrid: IEPALA Editorial, 1989. KI-ZERBO: Joseph: Historia del África Negra. Del siglo XIX a la época actual. Madrid: Alianza Editorial, 1980, vol. II. 
deraron las posiciones de cara a la descolonización por realismo político, no por ello negaron la necesidad de superar la dominación directa por medio de la transferencia del poder político a los grupos locales pro-occidentales.

Ante este panorama, desde los primeros años de la década de los cincuenta el Gobierno Portugués, imbuido de su convicción «colonialista» y previendo más o menos lo que se podía avecinar, ejecuta sus primeros movimientos sobre el tablero. En 1951 reforma la Constitución vistiéndola terminológicamente con conceptos más aceptables ante la realidad internacional emergente, lo que supuso pasar a llamar «Provincias Ultramarinas» a lo que hasta entonces eran "Colonias» y «Ultramar» al «Imperio Colonial Portugués» con la intención de reforzar legalmente la unidad «pluricontiental» de la «Nación Portuguesa». En esa revisión también se sancionó el objetivo de alcanzar una unidad económica de mercado entre Portugal y sus territorios extra-europeos en un futuro próximo. Y en 1954 se promulga el Estatuto dos Indígenas de Guiné, Angola e Moçambique, un diploma que mantiene el distingo legal entre ciudadanos de plenos derechos y nativos, pero que sin embargo concebía el indigenato como un estadio transitorio de los africanos que conduciría con el tiempo a su incorporación a la forma de vida europea y a que alcanzasen entonces la plenitud de derechos civiles.

En el plano práctico, Lisboa hubo de trabajar, partiendo de esas reformas legales y de los objetivos que aspiraban a defender, para forjar una teoría oficial lo suficientemente robusta como para afrontar la difícil partida que le aguardaba como miembro efectivo de la Asamblea General de las Naciones Unidas, condición que adquiere en diciembre de 1955. Como es comprensible, y dado que los primeros problemas para Portugal se manifestaron en Asia con las reclamaciones indias sobre el llamado Estado Português da India, donde las defensas de las que un país de las características de Portugal podía hacer uso no pasaban obviamente de una fuerza armada superior a la testimonial y ni siquiera disuasoria, obligó a que la diplomacia lusa se esforzase para que la arena de combate fuesen los organismos internacionales, las reglas de juego las marcadas por el Derecho Internacional, y el caballo de batalla la interpretación de éste y su adaptación a la casuística portuguesa.

Siguiendo tales planteamientos, las autoridades de Lisboa rechazaron frontalmente la negociación de la transferencia de sus posesiones en el Indostán a la Unión India, y esto fue así, entre otras cosas, por la convicción política de que esa aceptación supondría un precedente peligroso a la hora de defender lo sustancial del Imperio: las colonias africanas. De hecho, una vez el país fue admitido como miembro de la ONU, una de las primeras acciones emprendidas por sus diplomáticos fue la interposición de una denuncia ante el Tribunal Internacional de Justicia de La Haya contra la India por la ocupación de los enclaves portugueses interiores de Nagar-Aveli y Dadrá en 1954, consiguiendo así empantanar judicialmente las reivindicaciones de Nueva Delhi sobre el resto de los territorios lusos del Mar Arábigo. 
Desde el Gobierno se tenía la vaga esperanza de poder amortiguar el golpe descolonizador arguyendo: que por imperativo constitucional Portugal era una Nación pluricontinental y plurirracial indivisible; que Portugal había sido y era integrador y respetuoso con las comunidades colonizadas y como aval tenía una tradición secular y el ejemplo de Brasil; que no importaba el origen de la formación del territorio luso - la conquista-, sino la evidencia de la consolidación a esas alturas de una verdadera comunidad de destino compartida por las poblaciones de color; y que la Metrópoli portuguesa no era un país desarrollado y por tanto no se le podía acusar de haber logrado algo de lo que no disfruta a costa a la explotación de las Colonias. De ese modo, los espacios situados en continentes diferentes al europeo debían ser vistos como pequeñas porciones de la Patria fuera del solar ibérico originario ${ }^{10}$.

Valiéndose de la rectificación constitucional antes mencionada, cuando tras la entrada en las Naciones Unidas se le pregunta al representante portugués si su país administraba o no Territorios No Autónomos (TNA), éste respondió con una negación tajante. Según las autoridades lusas los espacios de ultramar eran «provincias". Es de ese modo como el Estado Novo se embarca en el exterior en una batalla «histórico-jurídica» que se prolongará hasta el final del Portugal salazarista, si bien es cierto que en una coyuntura muy diferente desde el inicio de la guerra en Angola ${ }^{11}$.

De cara a la legalidad internacional, la Dictadura sostiene que el Artículo $73^{\circ}$ del Capítulo XI de la Carta de las Naciones Unidas, en su punto e), que obliga a los Estados miembros a transmitir informaciones al Secretario General sobre los territorios coloniales, no era aplicable a Portugal, ya que esa transferencia de información dependía de la propia interpretación que el Estado en cuestión hiciese del concepto de TNA y de su aplicación a sus posesiones, y en el caso portugués no existirían «legalmente» espacios susceptibles de ser entendidos como colonias. Esta lógica argumental será obviamente calificada por los países afro-asiáticos y comunistas de «artificio legal», carente de toda realidad, como se desprendía de la reafirmación de un estatuto diferenciado entre ciudadanos e indígenas, de que los asuntos de esos territorios fuesen gestionados por órganos centralizados en la capital metropolitana, sin que en ellos se pudiesen escuchar los pareceres de sus poblaciones debidamente representadas, o a la vista de los índices de desarrollo humano del ultramar luso ${ }^{12}$.

10 RODRIGUES QUEIROS, Afonso: «Portugal e a descolonização». Conferencia pronunciada en la Facultad de Letras de la Universidad de Coimbra en 1 de diciembre de 1961. Coimbra, 1961. pp. 12-16.

11 MARTINS, Fernando: «A política externa do Estado Novo, o Ultramar e a ONU: Uma doutrina histórico-jurídica (1955-1968)». Penélope, no 18, 1997, pp. 189-206.

${ }^{12}$ La Carta de las Naciones Unidas, en su Capitulo XI, Artículo 73ㅜ, punto e) dice lo siguiente:

«Los Miembros de las Naciones Unidas que tengan o asuman la responsabilidad de administrar territorios cuyos pueblos no hayan alcanzado todavía la plenitud del gobierno propio, reconocen el principio de que los intereses de los habitantes de esos territorios están por encima de todo, aceptan como un encargo sagrado la obligación de promover en todo lo posible, dentro del sistema de paz y de seguridad 
En esta disputa política se enzarzarán los delegados portugueses en la Asamblea General, fundamentalmente detrás de la duda interpretativa que arrojan sobre la aplicación de algunos principios de la Carta, haciendo especial hincapié en que de no respetarse su lectura restrictiva del polémico Artículo 73ㄴ, se estaría vulnerando uno de los principios fundamentales de las relaciones internacionales desde Westfalia y sancionado en la propia Carta, «el derecho a la no injerencia en los asuntos internos de los Estados»'13, puesto que se violaría la legalidad constitucional de un Miembro. Tal controversia encauzará la querella por un proceso de discusión legal y político que aplazó su aclaración hasta el final de la década.

El principio del fin del litigio lo marcó la Resolución 1467 (XIV) de 12 de diciembre de 1959, que constituía el Comité de los Seis para esclarecer las cuestiones generales relativas a la transmisión y examen de información, o lo que es lo mismo, con el encargo expreso de determinar qué debería entenderse como TNA, la propia competencia de la ONU para gestionar tal asunto, y el alcance de la obligación que recogía la Carta para todos los estados miembros con posesiones susceptibles de ser así consideradas.

La trifurca legal urdida por Lisboa, apuntalada por la necesidad de que dos tercios de los representantes de la Asamblea votasen a favor de una resolución condenatoria y por la confianza que los portugueses tenían en la protección de las potencias occidentales en el Consejo de Seguridad, se vino a bajo sólo un año después.

A partir de diciembre de 1960, la cosas irían de mal en peor para la causa colonial portuguesa, y no harían más que complicarse con el inicio de la lucha de liberación en los primeros meses del año siguiente en Angola, evidencia que negaba la pretendida unidad de destino compartida por todos de Portugal y sus territorios ultramarinos ${ }^{14}$.

internacionales establecido por esta Carta, el bienestar de los habitantes de esos territorios, y asimismo se obligan:

e. a transmitir regularmente al Secretario General, a título informativo y dentro de los límites que la seguridad y consideraciones de orden constitucional requieran, la información estadística y de cualquier otra naturaleza técnica que verse sobre las condiciones económicas, sociales y educativas de los territorios por los cuales son respectivamente responsables, que no sean de los territorios a que se refieren los Capítulos XII y XIII de esta Carta».

${ }^{13}$ La Carta de las Naciones Unidas en su Capítulo II, Artículo 2º, epígrafe 7 dice:

«Ninguna disposición de esta Carta autorizará a las Naciones Unidas a intervenir en los asuntos que son esencialmente de la jurisdicción interna de los Estados, ni obligará, a los Miembros a someter dichos asuntos a procedimientos de arreglo conforme a la presente Carta; pero este principio no se opone a la aplicación de las medidas coercitivas prescritas en el Capítulo VIl».

${ }_{14}$ Para conocer mejor el discurrir de la posición portuguesa en las Naciones Unidas en estos años, vid.: MARTINS, Fernando: Ob. Cit, pp. 189-206. 


\section{UNA NUEVA DÉCADA Y UN NUEVO ESCENARIO. LAS CONDENAS INTERNACIONALES, LA GUERRA COLONIAL Y EL INMOVILISMO POLÍTICO}

Desde finales de 1959 a principios de 1962 el problema colonial portugués da un nuevo giro debido a alteraciones sustanciales en diferentes ámbitos: para empezar en las Naciones Unidas, donde la entrada de diecisiete nuevos Estados - de los cuales dieciséis eran africanos-, trastorna totalmente el equilibrio de poder en la Asamblea, donde la querella legalista portuguesa queda superada definitivamente en diciembre de 1960 y donde se verifica un cambio en la posición de Washington al adoptar la nueva administración demócrata una actitud menos condescendiente de cara a la política colonial de Lisboa desde marzo de 1961; en África, donde prácticamente los imperios francés y belga desaparecen, dejando en la vecindad de las posesiones portuguesas nuevos estados hostiles al colonialismo; en el propio interior del Imperio Portugués, concretamente en Angola, donde desde principios de 1961 se empieza a avisar de la inminencia de la guerra, que estalla en marzo; en Oriente, donde la India empieza a deslizarse hacia empleo de la fuerza para extinguir la presencia portuguesa en Goa y sus dependencias; y para terminar y como consecuencia de lo antedicho, en la propia Metrópoli, donde la situación crítica colonial e internacional del país desemboca en una tentativa de golpe de estado en abril de 1961 con el objetivo urgente de cambiar la política ultramarina suicida del Presidente del Consejo.

A la sombra de la nueva situación internacional en materia colonial, el deterioro de la posición lusa fuera de Europa se acentúa como resultado de uno de los elementos que propició la mayor veleidad de la ONU frente al obstruccionismo portugués: la alteración del equilibrio de poderes en la Asamblea General debido a la entrada de nuevos miembros del África Negra. Esos países recién incorporados a la Organización votarán en bloque en los asuntos relativos a la descolonización, tal y como las Conferencias Bandung y de Accra habían sellado, situación que se verá agravada para los intereses portugueses por los «vicios» de la competición Este/Oeste, que empuja a ambos bloques a buscar la atracción a sus filas de estos nuevos miembros de la comunidad internacional, y eso suponía para las superpotencias el alineamiento decidido con los principios anticolonialistas afro-asiáticos, colocando a Lisboa frente a la disyuntiva de: enfrentarse a un previsible aislamiento, a la condena internacional e incluso a las represalias de algunos países, o claudicar y perder el Imperio.

Tales circunstancias fueron las que llevaron a la aprobación el 14 de diciembre de 1960 de la Resolución $1514(X V)^{15}$, considerada el documento cumbre de la descolonización, en la que se reconoce el derecho de todos los pueblos dominados

15 Resolución 1514 (XV): Declaración sobre la concesión de la independencia a los países y pueblos coloniales. Aprobada el 14 de diciembre de 1960. En: Centro de Documentación de la ONU-Resoluciones de la Asamblea General: http://www.un.org/spanish/documents/resga.htm 
a su emancipación incondicional. Sólo un día después, tomando como base el Informe del Comité de los Seis se aprobaba la Resolución $1541(X V)^{16}$, en la que se especifican los elementos a observar para valorar si un espacio se debe considerar TNA o no, lo que quebraba la línea de defensa lusa. Y por si quedase alguna duda, ese extremo fue definitivamente confirmado por la Resolución $1542(X V)^{17}$ del mismo día 15 de diciembre de 1960, que refiriéndose específicamente a Portugal, califica todas sus posesiones extraeuropeas como TNA en aplicación de los criterios de la resolución anterior. La batalla legal había basculado en contra de los intereses de Lisboa ${ }^{18}$.

Pero el acceso a la independencia de nuevos estados africanos no sólo supuso un inconveniente en los «areópagos mundiales» para Lisboa, también significó para el Ultramar Portugués el temor fundado a la instalación al otro lado de sus fronteras de gobiernos nacidos en la hoguera anticolonialista, y por tanto comprometidos con la expulsión de los dominadores europeos del Continente, máxima que se sitúa por encima de las disputas territoriales o de las diferencias ideológicas que podían existir entre ellos. Lo dicho significaba que los nuevos poderes vecinos podrían dar origen a diferentes fricciones: unas por la falta de garantías de que los acuerdos que Lisboa tenía sellados con las antiguas metrópolis europeas fuesen a ser respetados; otras por la probabilidad de que se convirtiesen en un foco de inestabilidad transfronteriza con efectos perniciosos en términos sociales, económicos y políticos por compartir con las posesiones lusas poblaciones con lazos tribales, y debido a las grandes dificultades de orden interno que cabía esperar que padeciesen al despojarse de la tutela europea; y a esto habría que sumar además una inquietud aún mayor, la de que se transformasen en plataformas seguras en las que los independentistas podrían disfrutar de libertad para armarse y adiestrarse, y desde las que lanzar acciones subversivas sobre las «provincias" del país ibéri$\mathrm{co}$, sintiéndose a salvo de la respuesta gubernamental al poder golpear y replegarse fuera del alcance del Ejército Portugués, como pronto se verificaría.

A las puertas de 1961 Portugal se sitúa en la frontera de dos Áfricas que comparten el solar subsahariano: el África Negra independiente y hostil a la colonialismo y a la misma presencia de blancos en el Continente; y el África Austral, dominada por las minorías colonas que encuentran en el Apartheid de la Unión Sudafricana el epicentro de su resistencia frente a la mayoría negra de sus pobla-

\footnotetext{
16 Resolución 1541 (XV): Principios que deben servir de guía a los Estados Miembros para determinar si existe o no la obligación de transmitir la información que se pide en el inciso E del artículo 73 de la Carta. Aprobada el 15 de diciembre de 1960. Ibidem.

17 Resolución 1542 (XV): Transmisión de información en virtud del inciso E del artículo 73 de la Carta. Aprobada el 15 de diciembre de 1960. Ibidem.

${ }_{18}$ Ese mismo día Portugal quedaba más aislado aun en su defensa de la ilegalidad de las peticiones de la ONU para que remitiese información sobre sus Territorios No Autónomos, ya que España, que hasta entonces había esgrimido los mismos argumentos para negarse a hacerlo, cambió de opinión ante la perspectiva de que sus posesiones apareciesen en una resolución como TNA, aceptando in extremis transmitir la información requerida, lo que significaba reconocer implícitamente la condición de colonias de los espacios que desde 1958 calificaba también como provincias.
} 
ciones y contra los oponentes Estados negros del norte. Esto ponía a Lisboa ante un dilema: el de aceptar la conformación de un bloque blanco en el Sur recibiendo el apoyo de los Estados racistas, al ser coincidentes los intereses de éstos con la resistencia de Portugal como muralla de choque; o su rechazo por el problema de cara a la galería internacional que suponía mezclarse con los «proscritos» sudafricanos, y más cuando la doctrina oficial salazarista pretendía contraponer el «multirracismo» luso al segregacionismo de los afrikáners ${ }^{19}$. La opción seguida no sería ni la una ni la otra, sino un intermedia que salvaría las apariencias pero sin renunciar a la colaboración más o menos «informal» de los gobiernos racistas de Sudáfrica y de la Federación de Rhodesia y Niassalandia.

Ese aireado «multirracismo» portugués no pasaba de ser una elucubración teórica de la que se hará a partir de ahora uso y abuso al tomarla como argumento máximo que pretendía demostrar la condición de «caso único» del colonialismo «respetuoso e integrador» de los portugueses, un juego de medias verdades de cuya credibilidad podría depender en última instancia la mayor o menor complacencia de quienes realmente podían contribuir a la causa lusa de manera notoria, es decir, los grandes poderes occidentales, o por lo menos facilitar las cosas para que la fiscalización que las opiniones públicas de algunos países aliados ejercían sobre sus gobiernos en materia colonial se relajase, permitiéndoles ser más «comprensivos» con los deseos de Lisboa.

Sin embargo, y a pesar de los esfuerzos retóricos, de las repercusiones que las independencias de los vecinos tenían en los territorios controlados por Portugal, particularmente del Congo ex-belga; del aliento a los nacionalistas que la comunidad internacional les daba a través de la ONU; y del juego de bloques, sumado al desarrollo del nacionalismo angoleño, nació la concreción de los peores temores de Lisboa, que no eran otra cosa que un conflicto armado prendiese en alguna de sus «provincias», algo más que un contratiempo para sus aspiraciones conservacionistas de cara al veredicto de comunidad internacional, que tenía como siempre mucho que decir sobre futuro del Imperio Portugués.

En Lisboa ya se tenía conocimiento de los potenciales riesgos para la «integridad nacional» presentes en el propio interior de sus «provincias ultramarinas» al menos desde $1958^{20}$. Conocía la existencia de movimientos de liberación, y según

19 A. Oliveira Salazar da orden para que los representantes portugueses en Pretoria establezcan contactos de cooperación defensiva secreta con la República Sudafricana ante las manifestaciones en ese sentido hechas desde la capital sudafricana y también desde la Federación de Rhodesia y Niassalandia ya a mediados de 1960, pero nunca que comprometiesen a Portugal con el régimen del Apartheid. Documento de Antonio de Oliveira Salazar para la Defensa Nacional, fechado en 17/11/60. En ella manifiesta en relación a lo que antecede, su acuerdo con las observaciones del Jefe del Estado Mayor, en el interés de iniciar contactos de carácter técnico y secretos en materia de defensa con Sudáfrica. Arquivo Oliveira Salazar/Correspondencia Oficial/Ultramar-Caja 55, pp. 18-20.

20 Ya desde 1958 Portugal había puesto en marcha una rectificación en sus planteamientos de defensa nacional, dando prioridad a un potencial conflicto colonial frente a una hipotética guerra con el Este en Europa, lo que había llevado a que se empezase a comprar armamento adaptada a un tipo de conflicto diferente. Ver: TELO, Antonio: «Portugal. Os Estados Unidos e a NATO». En: NUNO RODRÍGUES, 
los informes de la Fuerzas Armadas, cabía esperar que tarde o temprano emergiesen situaciones conflictivas, peligro que era de prever que se manifestase: 0 bien en una lucha no convencional, de tipo subversivo con este tipo de organizaciones; o bien en enfrentamientos puntuales con alguna potencia vecina debido al proceso imparable de independencia de los dominios colindantes. Y como no podía ser de otra manera, no tardaron en manifestarse los primeros incidentes en Angola ${ }^{21}$.

El 12 de enero se registraban desordenes en Cassange y el 4 de febrero se producían importantes disturbios en Luanda, -éstos últimos reivindicados por el Movimento Popular de Liberaço de Angola (MPLA), de orientación marxista, aunque perpetrados por militantes en su mayoría de la União dos Povos de Angola (UPA) con el objetivo de aprovechar la presencia de numerosa prensa internacional en la capital angoleña, que aguardaba la llegada del oposicionista Henrique Galvão y del buque portugués Santa María, secuestrado en el mar Caribe como acto de rebeldía contra las dictadura ibéricas-, manifestándose en los días subsiguientes en forma de fuertes tensiones interraciales y represión policial. Ante estos acontecimientos, el asunto de Angola empieza a ser discutido en el Consejo de Seguridad el día 10 de marzo a iniciativa de los países afro-asiáticos, prolongándose hasta el día 15 de ese mes, el tiempo suficiente para que en el norte de Angola se iniciase la guerra y para que en Nueva York se tuviese conocimiento de ello. Obviamente la fecha de inicio de las acciones armadas que iban a afectar a los distritos del norte de la colonia — los limítrofes con el Congo-Leopoldville-, no fue elegida al azar por los nacionalistas de la UPA de Holden Roberto - movimiento de corte pro-occidental.

En esa reunión del Consejo de Seguridad, dadas las evidencias conocidas de la situación en la colonia y por las reiteradas negativas portuguesas a hacer caso a los llamamientos de la ONU, se presentó un proyecto de resolución en la que se pedía a Lisboa que tomase las medidas necesarias para permitir la aplicación de los presupuestos de la Resolución 1514 (XV) en Angola de forma urgente, al considerar que los hechos allí acaecidos representaban un riesgo para la paz mundial. En esta ocasión el texto fue rechazado al abstenerse seis de los once miembros del Consejo, votando a favor la Unión Soviética, República Árabe Unida, Ceilán, Liberia y los Estados Unidos. Sin embargo, más importante que el resultado de la votación fue el hecho de que por primera vez Washington se posicionaba más allá de la abstención contra Portugal, lo que constituyó para las opciones de resistencia y para el fuero interno de los portugueses un duro golpe. La llegada en enero de ese año de J. F. Kennedy a la Casa Blanca estaba dando paso a un cambio en el clima de las relaciones entre los dos países.

Luís (Coord.): Regímenes e Imperio: As Relações Luso-Americanas no Século XX. Lisboa, IPRT, 2006, pp. 45-86.

${ }_{21}$ Para la evolución del problema colonial portugués desde la perspectiva de la lucha de los movimientos de liberación, vid.: SÁNCHEZ CERVELLÓ, J.: El último imperio occidental: la descolonización portuguesa (1974-1975). Cuadernos de Estudios Luso-Españoles, ํㅡㄹ. Mérida: UNED, 1998, pp. 4-108. 
Ante este escenario, desde el estamento militar se inicia una acción destinada a cambiar el curso de los acontecimientos, y esa corrección pasaba por intentar apartar a Antonio Oliveira Salazar de la Presidencia del Consejo y mudar la actitud intransigente del Gobierno Portugués hacia la realidad emergente en Ultramar. El intento de golpe palaciego conocido como la «Abrilada» fue encabezado por le Ministro de Defensa Julio Botelho Moniz y secundado por otros altos mandos militares conocedores de la dimensión que una contienda colonial podía alcanzar, tal y como su observación de los ejemplos de Holanda en Indonesia, o Francia en Indochina y Argelia les había dejado claro, evidencia que a su entender superaba la capacidad individual del Estado Portugués en las condiciones de rechazo internacional en que se encontraba. Por defectos en su ejecución, y a pesar de contar con una actitud favorable de la administración Kennedy, la tentativa fracasó y la supervivencia de Salazar a la asonada del 13 de abril supuso la inmediata exoneración de los rebeldes y de su alternativa - la apertura del Régimen y una posible federación de las Colonias y la Metrópoli-, reforzando en el poder a los partidarios del inmovilismo. Se acallaron temporalmente las sutiles discrepancias de los militares reformistas del régimen y se selló el principio de «aguantar» como directiva inquebrantable, siendo cualquier otra alternativa considerada —al menos públicamente - una traición a la integridad de la Patria y una postración a los intereses extranjeros.

"Andar rápidamente e em força» para Angola, ese es el titular que el Presidente del Consejo da a la prensa lusa e internacional en su discurso del mismo día 13 de abril de 1961. El mantenimiento del padre del Estado Novo al timón, después del embate golpista, del inicio de la guerra, de desencadenados los ataques en la ONU, de la agudización del aislamiento internacional y hasta del abandono norteamericano, hace de su «titular» en sí mismo un autentico dogma político de gravísimas consecuencias.

A pesar del aparente fracaso en el Consejo de Seguridad, las naciones afroasiáticas, conscientes de su superioridad en la Asamblea, no aceptaron la derrota y presentaron allí la misma propuesta, siendo aprobada el 20 de abril de 1961 como Resolución 1603 (XV). Con ella también se crea la Comisión Especial de los Cinco, con el cometido de estudiar la verdadera dimensión del problema en Angola ${ }^{22}$. Y de nuevo la discusión vuelve al Consejo de Seguridad entre los días 6 y 9 de junio, saliendo aprobada como Resolución S/4835 de 9 de ese mismo mes, con un resultado de nueve votos a favor y ya solo dos abstenciones, las de Francia y Gran Bretaña ${ }^{23}$.

22 Resolución 1603 (XV): La Situación en Angola. Aprobada en 20 de abril de 1961. La Situación en Angola. En: Centro de Documentación de la ONU-Resoluciones de la Asamblea General: http://www.un.org/spanish/documents/ resga.htm

${ }^{23}$ Resolución del Consejo de Seguridad o 163 (S/4835): Cuestión relativa a Angola. Aprobada el 9 de junio de 1961. En: Centro de Documentación de la ONU-Resoluciones del Consejo de Seguridad: http://www.un.org/spanish/documents/scres.htm 
Aun le quedaba a la delegación portuguesa en las Naciones Unidas y a Portugal entero un último mal trago que pasar antes de que finalizase 1961. Después de reiteradas amenazas y de la escalada de fricciones a lo largo del año, el 18 de diciembre la Unión India consuma la invasión de Goa, Diu y Damão, y el Consejo de Seguridad, reunido de urgencia, fue incapaz de condenar la acción gracias al veto de la URSS, bajo cuya previsión —-según las autoridades del Régimen-, se ocultaría la falta de decisión de aliados como los EEUU.

De hecho, al día siguiente del veto soviético en el Consejo de Seguridad, de nuevo toda la Asamblea General vota a favor del documento presentado por la Cuarta Comisión, convirtiéndose en la Resolución 1699 (XVI) de 19 de diciembre ${ }^{24}$. Esta vez ya se condena expresamente la actitud del Gobierno Portugués por negarse a remitir la información a la que las resoluciones anteriores le obligaban, al tiempo que decide constituir la llamada Comisión Especial de los Siete para que indague por encima de Portugal la situación real de todos los TNA administrados por Lisboa, y llama a todos los Estados Miembros a que presionen para que el país ibérico acepte las directrices de la ONU.

Si en todo este periodo las resoluciones que atañían a la delicada posición de Portugal no fueron más violentas no fue porque ese tipo de propuestas no existiesen. En la mayor parte de las sesiones que se celebraron en la Asamblea, las naciones del bloque del Este no dejaron de presentar documentos alternativos que pedían la transferencia inmediata de la administración a los pueblos colonizados y el reconocimiento de algunos movimientos de liberación como únicos representantes de la soberanía de los territorios, sin que ello fuese inconveniente para que ante la imposibilidad de ver aprobadas sus textos, siempre votasen a favor de las más moderadas resoluciones afro-asiáticas contra Portugal, eso si, sin cejar en su empeño de que incluyesen medidas coercitivas concretas contra la actitud de Lisboa. La razón de la limitación de esos «llamamientos» o de esas «condenas» inconsecuentes - que sólo dejaban la puerta abierta a que cada Miembro adoptase las medidas que estimase oportunas-, fue la influencia de los aliados europeos y americanos, pero especialmente de Londres, París, Bonn (aunque la República Federal de Alemania no era miembro de la Organización) y de Washington. En éste último caso, si bien desde el ascenso de los demócratas al poder los EEUU estaban dispuestos a presionar para que Salazar tuviese que ceder, no querían ir al extremo de poner al país ibérico entre la espada y la pared, forzándolo a abandonar la ONU o incluso la OTAN, especialmente por el valor estratégico para la defensa occidental que tenía la Base de Lajes, en las Azores.

24 Resolución 1699 (XVI): Incumplimiento por parte de Portugal del Capítulo XI de la Carta de las Naciones Unidas y de la Resolución 1542 (XV) de la Asamblea General. Aprobada el 19 de diciembre de 1961. En: Centro de Documentación de la ONU-Resoluciones de la Asamblea General: http://www.un.org/spanish/documents/ resga.htm 


\section{LA POLÍTICA COLONIAL PORTUGUESA ANTE EL ESTALLIDO DE LA GUERRA EN ANGOLA}

Lisboa hace su propia radiografía de la realidad internacional y de su lugar en ella. Partiendo de la consciencia de su difícil posición para mantenerse a flote en África, concreta su respuesta en tres líneas de acción principales: la primera, la resistencia armada con el objetivo de contener la rebelión en el norte de Angola y aplastarla lo antes posible; una segunda basada en la «contrainformación», destinada «esclarecer el entendimiento occidental» y por supuesto a mantener el frente unido en el interior, propagando un discurso explicativo del problema acorde con los intereses del Estado; y por último, la adopción de reformas en materia colonial, concebidas para apoyar la ejecución de las anteriores y para frenar los riesgos de que prendiese una rebelión generalizada en todos los territorios dominados sustentada por la connivencia de la población negra y por una mayor implicación de los poderes internacionales. Tres líneas de acción que formaban parte de una política coherente, en tanto en cuanto era de la inserción internacional de Portugal de lo que dependía el mantenimiento del orden interno en las «provincias ultramarinas" y viceversa.

Comenzando por el principio, cabe decir que la contención del conflicto y su "silenciamiento» fueron sin duda los objetivo más inmediatos del Régimen en los primeros compases de la guerra. Del éxito de las acciones armadas de la UPA dependía el que la rebelión se extendiese por la provincia; que en un acto reflejo y oportunista acciones similares se reprodujesen en otras colonias; y que la comunidad internacional radicalizase sus posiciones en vista del evidente deseo de independencia de la población nativa. Esto último desmentía además la retórica portuguesa que sostenía que la «unidad nacional multiétnica y pluricontinental» era compartida por la población de color y desahuciaba la endeble excusa de que no había necesidad de hacer una consulta refrendataria para demostrar la voluntad política de seguir siendo portugueses de una población que supuestamente la venía poniendo de manifiesto en la cotidianeidad de la convivencia pacífica.

El objetivo militar era aislar a los insurrectos y alejarlos de la población negra, empujándolos hacia la frontera del Congo. Con ello se pretendía impedir que la propaganda de captación rebelde llegase a las masas, y probar que los responsables de las acciones eran principalmente extranjeros dirigidos por el comunismo internacional y no angoleños más que en un porcentaje mínimo. Se esperaba también salvar la producción de café de la provincia, concentrada en los distritos afectados, y de cuya recolección dependía el que buena parte de la población no padeciese los efectos del desempleo, lo que combinado con las actividades subversivas rebeldes podía ser peligroso. Y no menos importante era acallar el problema de cara a la galería internacional, donde los países más activos en la lucha anticolonial no dejaría de aprovechar cualquier noticia para descargar con mayor ferocidad sus críticas contra Portugal, e indirectamente contra los aliados de éste, procurando situarlos en posiciones comprometidas. 
En estos años los esfuerzos militares no fueron capaces de anular totalmente los ataques insurgentes, que se valían de la plataforma de incursión del Congo y de la connivencia voluntaria o forzada de la población dispersa del norte de la provincia, como tampoco pudieron impedir que un importante número de civiles angoleños se refugiase en el vecino del norte, dejando muchas haciendas sin trabajadores que recogiesen el café y una evidencia más de cara al mundo de la verdadera dimensión del problema de Angola. Sin embargo, lograron contener las agresiones en una área más o menos reducida y mantenerla en unos niveles tolerables en relativamente pocos meses, tal y como muestran los informes de las Fuerzas Armadas y como también atestiguan las delegaciones consulares extranjeras en la colonia. Pero la supervivencia del foco rebelde implicaba proseguir indefinidamente la política de contención y perpetuaba la necesidad de mantenerse alerta ante posibles rebrotes en otros puntos de la colonia o en el resto del Imperio, y para ello había que preparar al Ejército para un tipo de combate nuevo y dotarlo del material militar adecuado. Para avituallarse y formarse era preciso recurrir a la tecnología y a la experiencia de otras potencias occidentales con industrias armamentísticas más desarrolladas que la portuguesa, siendo aquí donde entraba en juego el segundo vector de la política colonial portuguesa, dividido en dos ámbitos de acción que giraban en trono a una misma teoría de defensa.

La labor de "esclarecimiento» emprendida por Portugal se vehiculó al interior a través de los medios de comunicación nacionales, controlados por la censura, valiéndose con éxito de la invocación del nacionalismo portugués. Sin embargo, de cara al exterior la obtención de resultados satisfactorios se hizo mucho más difícil, con la salvedad de en algunos países y territorios amigos como: España, la Unión Sudafricana o la Federación de Rhodesia y Niassalandia, y de medios conservadores de países occidentales como Francia, la República Federal de Alemania, Brasil o el Reino Unido. En este sentido, la importancia de la actividad diplomática adquiría una dimensión sobresaliente para los objetivos inmovilistas de Lisboa, siendo su cometido el ganarse la complicidad o la condescendencia de Occidente frente a los ataques y las presiones de los países afro-asiáticos y comunistas, de quienes no se podía esperar concesión alguna —-por lo menos en principio.

De la ayuda occidental dependía el avituallamiento militar necesario que antes mencionábamos, pero también las ayudas técnicas y económica necesaria para que Lisboa sacase adelante su política de fomento ultramarino acelerado, imprescindible entre otras cosas para: lavar su imagen, quitar argumentos a los acusadores más implacables de las vergüenzas de la dominación portuguesa, y para ganarse a nativos y colonos generando trabajo y ofreciendo mejores servicios públicos, con la ilusión de que estas mejoras alejasen a la población negra de la captación subversiva de los movimientos de liberación y a los blancos de buscar una alternativa política por su cuenta. Pero además, la comprensión de Occidente era un objetivo en términos meramente políticos de cara a la ONU, puesto que su actitud y su capacidad de influir en las posiciones de terceros, podría contribuir a mermar la imagen de aislamiento internacional del régimen portugués que tanta 
tensión creaba en el interior, podía relativizar la rotundidad de las condenas de su política colonial, y también impedir que se adoptasen sanciones concretas.

La teoría esgrimida para explicar la raíz de lo que estaba sucediendo en Angola consistió en la inculpación exclusiva del comunismo internacional. Los líderes del Régimen sostenían que en el tiempo de la paridad atómica se habría llegado a un «equilibrio de impotencia» que obligaba a la búsqueda de nuevos caminos en la confrontación Este/Oeste, y esos eran los de la guerra subversiva camuflada bajo el anticolonialismo, juego en el que Occidente nunca podría competir con el extremismo soviético. Tal conclusión la extraía Portugal al entender que el Este estaría desarrollando una triple acción contra el mundo capitalista agravada por la pasividad de éste, consistente en: la instigación y el apoyo material y táctico de las acciones de subversión el Asia y África de los nacionalistas para generar conflictos y expulsar a los europeos; el desarrollo de un plan diplomático destinado a atraer a las nuevas naciones independientes, llegando incluso a hacer uso indiscriminado del derecho de veto de la URSS en favor de cualquiera de ellas y contra el Mundo Libre; y la lucha para subvertir la legalidad internacional con el fin de acomodarla a sus necesidades y condenando los principios de Occidente.

Si bien esta lectura del problema podía ser suficiente para el consumo interno, no lo sería de cara a las cancillerías occidentales por el simple hecho de que, aunque fuese estrictamente cierta, no estaba completa. El problema colonial portugués debía en parte su naturaleza a la infiltración del comunismo, sin embargo encerraba también otros conflictos que no se podían pasar por alto: algunos de tipo tribal, el racial y por supuesto uno de lucha por la descolonización. Más aun, a pesar de que era precisamente el carácter de choque Este-Oeste el que más preocupaba a los aliados, ni por eso se manifestaron dispuestos a escuchar sinceramente las arengas lusas, dado que la solución que Lisboa proponía: la del apoyo incondicional de Occidente a la resistencia armada del país ibérico en Angola, por ser un punto importante para frenar la expansión del comunismo en África e impedir con ello el debilitamiento de Europa, era precisamente la opción contraria a la que los miembros de la OTAN entendían como lógica, siendo esta la de la transferencia de la administración de los territorios coloniales a los movimientos de liberación prooccidentales, como por ejemplo a favor de la UPA, que era quien sostenía la guerra con Portugal.

Obviamente no fue por esa vía por la que la diplomacia lusa alcanzó los resultados de que se pudo beneficiar para resistir en estos primeros momentos en África. Estos se consiguieron gracias a que Salazar pudo aprovechar algunos ases en la manga a la hora de tratar bilateralmente con algunos de sus aliados.

No está del todo claro qué tipo de apoyo logístico, diplomático, económico y hasta militar pudieron ofrecer países como España o la Unión Sudafricana a Portugal, aunque cabe suponer que éste tuviese una importancia notable. Por contra, sí sabemos que inicialmente tanto Gran Bretaña como los EEUU ayudaron a que las resoluciones de la ONU fuesen bastante moderadas, y que en el caso del Rei- 
no Unido, a pesar de acatar las prohibiciones de venta de armamento al régimen portugués ${ }^{25}$, en los primeros momentos sí suministró material de guerra bajo el subterfugio de la cooperación en el marco de la Alianza Atlántica y con la excusa de que Londres no era responsable del uso posterior que Lisboa diese a ese material. Otros países fueron más allá en su apoyo, particularmente la Francia de Charles De Gaulle o la RFA de Konrad Adenauer, convirtiéndose ambos en los principales surtidores de tecnología militar de Portugal, tanto de equipamiento naval como de armas ligeras, municiones y especialmente con la venta de aeronaves adecuadas para la lucha contra la guerrilla.

En el caso de las negociaciones con Washington, fue la importancia de las Azores para la conexión sur de los EEUU y Europa en la estrategia de defensa occidental lo que permitió contener las veleidades de J.F. Kennedy a partir de mediados de $1962^{26}$. En cuanto a los casos francés y alemán, su implicación más decidida derivó de las percepciones geoestratégicas de cada uno de ellos, de los planes para la consolidación de su poder en el mundo y de lo que Portugal les podía ofrecer a cambio de su ayuda económico-militar.

De cara a Bonn, Lisboa se aprovechó de la prioridad concedida por las autoridades conservadoras a la defensa nacional de un posible ataque soviético basada en la convicción de que el combate en los primeros compases se libraría sobre territorio alemán y del resto de sus vecinos, por lo que para garantizar una respuesta flexible era necesario un punto retrasado que ofreciese el soporte logístico preciso desde el que las fuerzas alemanas y aliadas pudiesen operar, donde almacenar armamento de reserva y adonde enviar los heridos, y eso lo ofrecía la seguridad del otro lado de los Pirineos, y por cuestiones de decoro político el candidato idóneo a prestar ese servicio era Portugal. Esta primacía de los criterios de Defensa terminaron por imponer las líneas de acción de la política exterior alemana, y por eso desde 1959 los contactos entre ambos países empezaron a caminar hacia la conclusión de múltiples acuerdos en pocos años, cuya manifestación más visible fue la concesión de una base área de entrenamiento a los alemanes en Beja en diciembre de 1960, además del almacenamiento en Portugal de grandes cantidades de municiones y el compromiso de asistir militarmente a las fuerzas alemanas en caso de guerra. A cambio, la RFA aportaba a Portugal un sustancioso apoyo a su desarrollo económico e indirectamente al de sus colonias y permitió la exportación de armamento de fabricación germana y excedentario de su ejército, siendo inmediatamente destinado a África por el régimen de Salazar. Y esto fue así a pesar de que para los responsables de Asuntos Exteriores de la RFA el que los nuevos estados descolonizados no reconociesen a la RDA era un obje-

${ }^{25}$ La primera texto que hace un llamamiento a los Estados Miembros para que no ayuden a Portugal a sostener la guerra en Angola, lo que lógicamente incluía el suministro de armamento, es la Resolución 1699 (XVI) de 19 de diciembre de 1961.

${ }^{26}$ NUNO RODRÍGUES, Luís: «A Administração Johnson e a Questão Colonial Portuguesa: O Plano Anderson". En: NUNO RODRÍGUES, Luís (Coord.): Regímenes e Imperio: As Relações Luso-Americanas no Século XX. Lisboa, IPRT, 2006, pp. 90-93. 
tivo especialmente deseado y al que poco ayudaba la colaboración con los portugueses. Sin embargo, ese desequilibrio favorable a los criterios del Ministerio de Defensa hacia Portugal frente los argumentos de Exteriores se mantendría en Bonn al menos hasta la segunda mitad de la década de los sesenta ${ }^{27}$.

Por su parte, la llegada de De Gaulle a la presidencia francesa si bien creó desconfianza en Lisboa por la inclinación que pronto demostraría a conceder la independencia a toda el África francesa, incluida Argelia, se superó por el papal que Portugal jugaba en los planes de afianzamiento francés en el mundo bipolar y especialmente en el hemisferio occidental. El desprecio del gaullismo por la ONU y su voluntad de ganar autonomía respecto a la dirección de los EEUU, le empujaron a seguir actuando de manera benevolente con Lisboa en su contencioso ultramarino. El país ibérico era un buen aliado con el que incomodar a Washington, y además podía ofrecer a Francia algo que necesitaba para el desarrollo de sus planes armamentísticos: por una parte, un importante mercado para sus fábricas y sus astilleros militares, y por la otra, un emplazamiento adecuado en la isla azoriana de las Flores para que París experimentase con su propio sistema de misiles balísticos capaz de contener las ojivas nucleares del programa Force de frappe. A cambio, Francia suministraría armamento adecuado para la lucha contra la insurgencia y apoyaría diplomáticamente en las Naciones Unidas a Portugal, pudiendo además moderar a algunos países tercermundistas dada la gran influencia que conservaba sobre las que pronto serían sus ex-colonias ${ }^{28}$.

Gracias a estas contribuciones y a que el conflicto no prendió entonces en otras colonias, Portugal pudo aguantar el primer envite del independentismo angoleño, si bien es cierto que con grandes esfuerzos militares, importantes sacrificios económicos y a costa de su credibilidad internacional.

\section{LAS REFORMAS DE ADRIANO MOREIRA}

La teoría ventilada por los dirigentes portugueses después de 1961 frente al mundo y ante la ciudadanía siguió siendo la misma, la basada en la particularidad de su hecho colonial, y para ello no tuvieron reparos en negar las evidencias más sangrantes de las deficiencias de su colonialismo. Se minimizó el atraso socioeconómico de las colonias lusas y con ello las carencias de la «obra de Portugal»; se negó la falta de autonomía política basándose en la letra de la Constitución que la reconocía, si bien de hecho era inexistente; se defendió que el distingo entre ciudadanos portugueses e indígenas del Estatuto de 1954 no era otras cosa que un

27 Ver: FONSECA, Ana Mónica: A Força das Armas: O Apoio da República Federal da Alemanha ao Estado Novo(1958-1968). Instituto Diplomático, Colecção Biblioteca Diplomática, Serie D, Número 7, Ministerio dos Negocios Estrangeiros, 2007.

28 Ver: SILVA COSTA MARCOS, Daniel da: Salazar e De Gaulle: A França e a Questão Colonial Portuguesa 1958-1968). Instituto Diplomático, Colecção Biblioteca Diplomática, Serie D, Número 8, Ministerio dos Negocios Estrangeiros, 2007. 
ejemplo más de la actitud respetuosa de Lisboa con las tradiciones y formas de vida de los naturales, recalcando que el diploma recogía ante todo el carácter transitorio del indigenato; a la falta de personal nativo en la administración colonial se respondió que era resultado de la baja cualificación de los habitantes de color, y que la simple coincidencia de la fractura educativa con la étnica no era motivo para acusar a Portugal de discriminación racial; etc. Todo un rosario argumental difícil de sostener que conformaba la «verdad» de Portugal.

Sin embargo, la evidencia de la necesidad de acometer algunas revisiones de la situación colonial portuguesa, propició que entre 1961 y principios de 1963 se fuese ejecutando un paquete importante de reformas coloniales. Y esto será nuestra tercera vía de acción a analizar.

En el mismo día que se detiene el intento de golpe de la «Abrilada», el 13 de ese mes de abril de 1961, se produce la primera remodelación ministerial en tiempos de guerra, un cambio de carteras precipitado por las circunstancias y que afecta a todos los altos cargos militares implicados en el golpe frustrado, siendo asumida la dirección del Ministerio de Defensa por el propio Oliveira Salazar - tal y como había hecho en los momentos pretéritos más delicados para Portugal, a lo largo de la Guerra Civil de España y durante la Segunda Guerra Mundial-, y en la que se aprovecha para reemplazar al contra-almirante Vasco Lopes Alves en la cartera de Ultramar por Adriano Moreria.

La opción de Adriano Moreira obviamente no se había hecho al azar, y menos en una situación crítica como la que afrontaba Portugal tanto en las colonias como en el exterior. Se puede decir de él que a parte de ser un hombre con alta cualificación técnica en el terreno legal, y de estar muy familiarizado con las problemáticas de las provincias ultramarinas por los estudios que había realizado, tenía experiencia en la administración colonial, era un civil, un orador brillante y podía acreditar además el ser un buen conocedor de la dimensión internacional del problema ultramarino portugués ${ }^{29}$. Aptitudinalmente, Adriano Moreira era un candidato idóneo para acometer, con la debida habilidad, las reformas que desde la cúspide del poder se valoraban como urgentes, sin olvidar tampoco la otra ventaja que poseía, que es que antes de su ascenso a la Subsecretaría de Estado de

${ }^{29}$ Adriano José Alves Moreira (1922- ): Licenciado en Ciencias Histórico-Jurídicas por la Facultad de Derecho de la Universidad de Lisboa, desde marzo de 1960 venía desempeñando el cargo de Subsecretario de Estado de Administración Ultramarina. Además de esta experiencia, era autor de una vasta e interesante bibliografía sobre temas ultramarinos y jurídicos. De hecho, en 1956 había recibido el Premio Abílio Lopes de Rego, de la Academia das Ciências de Lisboa, por su obra O Problema Prisional do Ultramar. Dos años antes había alcanzado la plaza de profesor ordinario del Curso de Administração Ultramarina, en el Instituto Superior de Estudos Ultramarinos, institución de la que sería director poco después, en junio de 1958. Fue nombrado director del Centro de Estudos Políticos e Sociais da Junta de Investigações do Ultramar, del que además había sido fundador. Y desde 1952, había participado en diversas conferencias internacionales con relevancia ultramarina, siendo miembro de algunas de ellas en esas fechas. Además de vocal de las secciones consultivas de del Conselho Ultramarino y procurador de la Câmara Corporativa, había formado parte de la delegación portuguesa en los XI, XII, XIII y XIV Periodos de Sesiones de la Asamblea General de las Naciones Unidas. 
Administraçâo Ultramarina en 1960 no había ostentado cargos políticos importantes, lo que le había permitido presentarse como un aspirante no «quemado» por el desempeño público y tampoco muy implicado en las luchas intestinas de la flor innata de la clase política del Régimen, al no haberse desmarcado de una forma clara hacia ninguno de los dos campos en liza, los «marcelistas» o renovadores y los «Costistas» o inmovilistas ${ }^{30}$.

Ya en su obra: Portugal e o Artigo 73 da Carta das Nações Unidas de 1957, alcanzaba a ver lo que aguardaba a Portugal en África:

«A batalha parlamentar [en la ONU] continuará; mas a batalha mais importante é a que se travará em África, com os meios de propaganda, de infiltração subversiva, de descrédito e, quando possível e oportuno de sedição. (...) é para ela que devemos estar preparados, baseados nestas premissas fundamentais: a comunidade luso-brasileira; a amizade luso-espanhola; a coerência interna entre a nossa doutrina e a nossa acção» ${ }^{31}$.

La búsqueda de esa coincidencia entre la doctrina y la práctica, o al menos la apariencia legal de coincidencia, es hacia donde se encaminarían las reformas de Moreira, unas rectificaciones que siguen además el camino que Paulo Cunha había trazado en su discurso de 9 de diciembre de 1960, con ocasión de su toma de posesión como Presidente del nuevo Conselho Superior de Política Ultramarina, en cuyo alegato se pudo escuchar:

«(...) Há muito que fazer ainda. Importa acelerar a obra en curso. Temos de realizar em poucos anos o que em velhos tempos normais se podia protrair por décadas. Há que continuar construindo, no plano material e no plano social, e que ir vigilando e defendendo. Há que preparar as coisas e vigorar os ânimos para que as procelas que se divisam não nos colham de surpresa. Há que povoar mais e mais. Há que aumentar os meios de educação e assitência social. Há que fomentar, com acrescida energia, o desenvolvimento da estrutura económica. Há que insistir na política de boa vicinhança e de boas relações com todos os países vicinhos, designadamente pelo esclarecimento dos novos países africanos das peculiaridades do caso português (...). Há que bradar ao mundo e a nós mesmos sobretudo à nossa gente nova- quais são as diferenças radicais entre o regime ultramarino de Portugal, (...) e os outros regimes de mau colonialismo (...). Há que assimilar e integrar mais ainda às gentes»32.

\footnotetext{
30 En palabras del que fuera Ministro de Exteriores, Franco Nogueira, sobre el nombramiento de Adriano Moreira como Subsecretario de Estado de Administración Ultramarina: «Se trata de un hombre nuevo, ideológicamente oriundo de la izquierda moderada, de alta inteligencia, de cultura política por encima de lo común, y que se había granjeado alguna fama como estudioso de cuestiones ultramarinas; además de eso es un nombre que en los sectores políticos no aparecía ligado a intereses o fuerzas económicas, ni se le considera quemado por actividades dentro del régimen. En: FRANCO NOGUEIRA, Alberto: Salazar. A resistencia (1958-1964), Vol.V. Oporto: Civilização, 2000, p. 116.

31 MOREIRA, Adriano: «Portugal e o Artigo 73ํda Carta das Nações Unidas». Lisboa, 1957, p. 36.

32 Discurso de toma de posesión de Paulo Cunha como presidente del Conselho Superior de Política Ultramarina, de 9 de diciembre de 1960. En: Boletim Geral do Ultramar, nํ 427-428, enero-febrero de 1961. Lisboa: Agência Geral Do Ultramar, pp. 335 y 336.
} 
Los objetivos de estas medidas serán: por un parte rebajar las críticas internacionales limando los elementos más deleznables del régimen colonial portugués, y con ello confiar en poder ganarse la condescendencia occidental y los beneficios que de ella se podrían granjear; y por la otra, mejorar la situación de la población nativa y colona para impedir su desafección hacia el proyecto del Estado, particularmente peligrosa en el caso de la de color, que podía tornarse colaboracionista con los independentistas.

Esas reformas podemos agruparlas en tres categorías: económicas, ya que era necesario fomentar el desarrollo de la actividad productiva «provincial» para dar empleo a los colonos que fuesen llegando y a los nativos, alejándolos de una subsistencia mísera y así de pensar en posibles salidas al problema fuera de las ofrecidas por la Metrópoli; sociales, basadas en las mejoras en materia laboral, educativa y sanitaria; y por último, las político-administrativas, especialmente importante de cara a la defensa de la posición lusa en los foros mundiales.

Desde su ascenso, el nuevo ministro fue desgranado lo que iban a ser sus prioridades políticas para el Ultramar y las razones que sustentan el programa reformador que espera acometer, eso si, siempre forzando una explicación que no contradijese las excusas dadas como respuesta por el Régimen a las acusaciones internacionales de colonialismo, y a pesar de que evidentemente estas imputaciones vehementemente negadas pretendían ser corregidas, o por lo menos maquilladas, con las reformas.

La consciencia de la importancia de que éstas fuesen ejecutadas, y previendo cierto rechazo a las mismas, hizo que Moreira se esforzase por hacer comprender a los interlocutores (militares, empresarios, misioneros, ciudadanos metropolitanos, colonos, etc.), el estado de excepción en el que la supervivencia del Portugal pluricontinental se encontraba y que ello era justificación suficiente para la ejecución de los cambios proyectados, por lo que no debían cuestionarse. Algunas sería molestas para ciertos colectivos, otras incluso lesivas, pero había que recalcar que también eran imprescindibles, dado que la defensa de los intereses particulares no era posible fuera del compromiso de resistencia del Estado, y éste no podría aguantar sin algunas correcciones.

En el terreno económico cabe decir que Portugal acometió un notorio esfuerzo inversor destinado a la construcci $n$ de infraestructuras, se llamó al capital nacional para asistir a los esfuerzos del Estado — que era quien garantizaba las inversiones y los negocios que los capitalistas lusos ya tenían allí-, y también se procuró atraer a inversores extranjeros. De estos últimos además de generar puestos de trabajo y riqueza, se esperaba que ayudasen a moderar la actitud reticentes de los gobiernos de sus países de origen respecto a la política colonial portuguesa, aunque también se autorizaron inversiones a capitalistas de determinadas nacionalidades con el objetivo de «premiar» a los países aliados más próximos. 
Desde el inicio de la guerra en Angola las partidas presupuestarias dedicadas a Ultramar fueron creciendo de manera constante, de modo que en 1962 la cuantía global multiplicaban por cuatro el presupuesto de 1959 - año en el que se había alcanzado el techo inversor de la década anterior. Si bien es verdad que esos capitales se movilizaron principalmente para sufragar auxiliarmente los costes de las operaciones militares - siendo la media de las partidas destinadas a gastos de esa naturaleza entre 1960 y 1963 del 79\% del total, no hay que olvidar que también generaron riqueza al mantener el consumo de los soldados y al financiar obras como aeródromos, carreteras, arreglos portuarios etc. que requerían mano de obra. Pero hay que señalar que a pesar de que la partida civil de los presupuestos fuese inferior, también experimento un notable incremento, y en este caso los fondos se encauzaría, a parte de los gastos corrientes de la administración colonial, a obras sociales, como: acondicionamientos urbanos, apertura de escuelas primarias y secundarias o a la mejora de los servicios sanitarios, además de a proyectos de asentamiento de colonos en emplazamientos de colonización agrícola, a la sedentarización de nativos, y al desarrollo de infraestructuras hidráulicas y energéticas especialmente necesarias para ayudar al despegue económico colonial.

En Lisboa se sabía que desde ahora su política de fomento entraría en una competición de méritos con los de sus vecinos negros y blancos, tanto a los ojos de la comunidad internacional hostil, como también de sus habitantes. Pero el crecimiento de la inversión del Estado pretendía ser además de una respuesta a las críticas, un ejemplo y una garantía de compromiso con la resistencia en África para los inversores nacionales y extranjeros, a los que había que dar garantías no ya para que no se produjese la fuga de los capitales que ya estaban allí, sino para que aceptasen el riesgo de hacer nuevas inversione en unos espacios con futuros políticos inciertos.

De todas maneras, el proyecto estrella en materia económica fue la creación del Espaço Económico Português (EEP), un plan controvertido que fue presentado en noviembre de 1961 por uno de los hombres de confianza de Oliveira Salazar: José Correia de Oliveira ${ }^{33}$.

EI EEP pretendía la integración económica imperial bajo razonamientos de carácter económico, pero también político, y así lo expuso el que pronto sería Ministro de Estado. En primer argumento era el refuerzo de la unidad nacional y la ejecución de los principios constitucionales: «Muito mais do que o aumento da riqueza material —que aliás só por si a justificaria—, está em causa a nossa própria concepção nacional e, por vía dela, a pátria portuguesa. A política proposta é, assim, a projecção inequívoca, no plano da economía, de uma atitude, de um con-

${ }^{33}$ Los orígenes del Espaço Económico Português hay que buscarlos en las directrices marcadas en el Acto Colonial, integrado en la Constitución en 1951, concretándose en el Decreto-Ley 43.016 de 8 de noviembre de 1961. 
ceito unitário da Nação »34. Pero además su intención era también suprimir todos los elementos que hiciesen pensar en un beneficio de la Metrópoli a costa de las «provincias» de allende-mar, piénsese en los elementos característicos del pacto colonial resucitado, que reserva esos espacios para las mercancías no competitivas de Portugal y les impide producir otra cosa que no sea, fundamentalmente, materias primas.

En cuanto a las justificaciones meramente económicas, el estímulo del desarrollo conjunto era la principal, confiando en poder corregir problemas como: la pervivencia de mercados internos muy pequeños en número de consumidores y en capacidad adquisitiva; la inadecuación del tamaño de las empresas nacionales por estar el mercado imperial fragmentado; los problemas que suponía el solapamiento de políticas económicas diferentes; el hecho de que en muchos casos esta dinámica llevaría no a la complementariedad natural ordenada por el mercado, sino a la concurrencia inútil entre empresas improductivas y sobreprotegidas; y para el estímulo de la productividad por la libre competición entre las más adecuadas a nivel estatal35.

El proyecto se basaba en tres principios de actuación. El primero, uno progresivo de reducción de las barreras aduaneras interregionales - que ya eran discriminatorias para las mercancías extranjeras-, imponiendo una merma más acelerada de las defensas metropolitanas de cara a los productos ultramarinos, dado al mayor desarrollo del Portugal continental, mientras que se fijaba plazos más dilatados para el desarme de las «provincias» con autonomía aduanera, fijándose en el horizonte diciembre de 1971 como fecha en la que deberían quedar suprimidas todas las trabas a la libre circulación de mercancías en el interior del EEP. En segundo lugar, una política específica de fomento y corrección económica en aquellas partes del Imperio menos evolucionadas y más vulnerables, destinada a buscar la convergencia en cuanto a los niveles de desarrollo económico, la competitividad y la complementariedad productiva en la medida de lo posible. Y como tercer pilar del proyecto, el Sistema Interterritorial de Pagamentos, que recogía la conformación de un mecanismo cambiario - cada parte del imperio tenía su propia moneda- para cubrir las previsibles distorsiones que la supresión de las limitaciones a las exportaciones metropolitanas hacia Ultramar y la progresiva rebaja de los aranceles provinciales provocarían, concretamente la generación de un déficit permanente de pagos entre las colonias, con divisas reducidas para pagar las importaciones del Portugal continental y una propensión creciente a adquirir cada vez más productos de los que podrían pagar en un plazo razonable.

${ }^{34}$ CORREIA DE OLIVEIRA, J.: «A integracão económica do Estaço Português». Comunicado de prensa del Ministro de Estado, de 3 de septiembre de 1962. En: Boletim Geral do Ultramar, n 446-447, agosto-septiembre de 1962. Lisboa: Agência Geral do Ultramar, p. 4.

${ }^{35}$ CORREIA DE OLIVEIRA, J.: «Unidade económica nacional. Directrices de acção no campo da actividade económica». Comunicado de prensa del Ministro del 23 de junio de 1961. En: Boletim Geral do Ultramar, no 434-435, agosto-septiembre de 1961. Lisboa: Agência Geral do Ultramar, pp. 29-44. 
Como un objetivo a largo plazo estaba también la idea de llegar a una moneda única, y la deslocalización de algunas industrias metropolitanas que basaban su actividad en el empleo de mucha mano de obra barata y poco cualificación, generando productos de bajo valor añadido, hacia las colonias, donde los costes de producción eran menores por ser los salarios también inferiores, con lo que también se esperaba ampliar la capacidad adquisitiva de los mercados coloniales y mudar la estructura productiva portuguesa.

A medio camino entre las políticas económicas y las sociales están las revisiones de la legislación laboral que ya se venían haciendo desde 1960, y que continuarían de la mano de Moreira. Ya en junio de ese año Portugal se adhería a la supresión de las sanciones penales por quebrantar los contratos laborales, vigentes aún en las colonias y que la Organización Internacional del Trabajo había aprobado en 1955; también uniformizó los criterios de fijación de los salarios mínimos y se daba total libertad contractual para el acuerdo de salarios superiores al más bajo permitido; se extendía a todo el territorio nacional la negociación colectiva para la concreción de los convenios colectivos; se empleaba a aplicar en Ultramar la regulación de seguridad e higiene industrial aprobada por la O.I.T; y ya bajo la dirección del nuevo ministro, el 2 de mayo de 1961 se aprobaba por Decreto-Ley 43.637 la creación de las Inspecções de Trabalho, destinadas a la vigilancia de que las disposiciones laborales anteriores se respetasen, el 27 de abril de 1962, por el Decreto-Ley 44.309, se renovaba el Código do Trabalho Rural en vigor desde 1928 , adaptándolo a las nuevas contingencias laborales y políticas, y para apoyar la aplicación de estas disposiciones se creaban los Fundos de Acção Social no Trabalho, pensados para promover el conocimiento entre los trabajadores de sus nuevos derechos y deberes laborales.

Tantas veces como Moreira llamó al capital privado a participar en el proyecto luso y en la lucha contra la descolonización, o como defendió para el sector público un nuevo orden de prioridades a la hora de emprender proyectos, tantas o más se refirió en el marco social a la necesidad de tomar medidas destinadas a tapar la segunda vía por la que el foco infeccioso de la sedición podía colarse, el del equilibrio convivencial afectado por la discriminación racial.

La misma razón que hacía necesario el desarrollo económico acelerado en UItramar, la de viabilizar el proyecto político portugués ante los ciudadanos y ante la comunidad internacional, sustentaba también la política social del Régimen. Lo que se planeaba era en este caso un trabajo de revisión legislativa de eliminación de «situaciones coloniales», pero ante todo, las reformas implicaban un esfuerzo desproporcionado para ganarse a los nativos y para luchar contra las inercias heredades del pasado modificando las mentalidades.

Una de las medidas de carácter social más deseadas en las grandes tierras del África continental fue la abolición del régimen de cultivos obligatorios, que empu- 
jaban a los campesinos nativos que cultivaban algodón, ricino, arroz, etc. al borde de la subsistencia, exponiéndolos a los abusos de unos compradores blancos que no teína competencia - el territorio estaba dividido en áreas donde sólo un mayorista podía adquirir la cosecha de sus productores- y que disfrutaban de precios fijados oficilmente muy bajos. Por eso se abordó la rectificación con la máxima celeridad, ya que esos cultivadores, ocupados en las áreas rurales donde el control portugués era más débil, y en muchos casos próximos a las fronteras con otros países independientes — como en el caso de Mozambique-, eran el caldo de cultivo idóneo para la infiltración independentista. Así, por el Decreto-Lei 43.637 de 2 de mayo de 1961, sólo 19 días después de su toma de posesión de Adriano Moreira como nuevo Ministro, se suprimía la obligatoriedad de cultivar algodón, el caso más problemático, y a renglón seguido se procedió al estudio de la supresión también para el resto de cultivos compelidos.

Otros muchos asuntos requerían la atención de los reformadores. Uno de ellos el problema de la colonización con blancos de las dos principales provincias lusas del Ultramar. Las principales dificultades que esto encerraba eran la planificación necesaria para hacer viables económica y socialmente los asentamientos, y por la otra, el problema de la ocupación de tierras, punto controvertido que atraía sobre Lisboa un torrente de críticas internacionales por tratarse de una práctica clara de usurpación de los medios de vida a los nativos y de explotación de los recursos de esos territorios en beneficio de los europeos. Por eso, el 6 de septiembre de 1961, se aprobaban los decretos-ley: 43.894, que regulaba el reparto de tierras en Ultramar, para minimizar el impacto de la llegada de estas poblaciones alienígenas sobre las comunidades nativas y sus territorios; y 43.895 , que creaba las Juntas Provinciais de Povoamento, encargadas de promover y planear adecuadamente el asentamiento del torrente de colonos que se pretendía enviar a las colonias.

Para Portugal, la población blanca cumplía un importante papel en cuanto al desarrollo económico de las provincias, ampliando el número de consumidores y desarrollando algunas actividades de interés, particularmente en los centros urbanos. Pero además, el valor político del asentamiento de europeos se pensaba que sería netamente beneficioso, al entenderlos como «depositarios de la soberanía», o por lo menos detentadores de unos «derechos sociales» que obligarían a los que querían expulsar a Portugal del Continente a tener su futuro en cuenta y eso a pesar del desmentido que los ejemplos de Argelia y Kenia estaba dando. Incluso en términos contra-subversivos estas poblaciones podían ser un peón más en la lucha contra los rebeldes, particularmente por su papel de agentes opositores a los independentistas en las áreas rurales donde el control de las Fuerzas Armadas era más difícil, especialmente al concebirse también en los planes de colonización como deseable la sedentarización de los nativos nómadas en tierras cercadas individual o colectivamente. Este último objetivos se pone especialmente de relieve con la voluntad inicial de que los soldados allí destacados se fijasen en tierras repartidas, comenzando sus nuevas vidas en Angola, Mozambi- 
que o Guinea, lo que previsiblemente les convertiría en una fuerza de choque aún más eficaz, tal y como A. Moreira declara:

«Para isso vão ser instituidas a Juntas de Povoamento, que serão desde já instaladas em Angola e Moçambique, (...). Deste modo esperamos que se definam e realizem a tempo as condições indispensáveis para fixar designadamente os jovens que ali se encontram em serviço militar, e que têm defendido a soberania nacional com bravura que apenas se encontra em quem está a defender a sua própria terra»36.

Otro de los aspectos más importantes de esta rectificación de la política social ultramarina fue el esfuerzo por incrementar los niveles de educación primaria, secundaria y hasta la creación de universidades en las dos principales colonias portuguesas. Un importante paso en ese sentido se daría con la constitución en la primera mitad de 1962 de la Escolas de Magisterio Primario, proyectándose la instalación de dos en Mozambique y otras dos en Angola, con el objetivo de formar in situ a un mayor número de profesores de enseñanza básica, dadas las necesidades de atender el aumento de las escuelas primarias.

Pero en el campo de la educación el proyecto más importante fue la apertura de centros de estudios universitarios en las colonias, uno en Mozambique y otro en Angola, intención que Adriano Moreira ya adelantaba en su primer viaje como encargado de la cartera de Ultramar a las colonias, en el mes de mayo de 1961, refiriéndose a ello como una de las soluciones para cubrir el déficit de técnicos que la administración y la actividades económicas de las provincias precisaban para no estrangular el desarrollo perseguido. Después de un largo proceso de discusión y no pocos incidentes, en junio de 1962 se aprobaba el decreto de creación de los Estudos Gerais Universitarios en Angola y Moçambique, quedando pospuesta su apertura para el año académico 1963-64.

Para terminar, sólo nos queda mencionar las reformas en el área político-administrativa. Fue en este terreno donde las alteraciones tal vez fuesen las más llamativas por dar respuesta a algunos de los aspectos más incómodos del colonialismo portugués, pero también cabe decir que fueron al tiempo las más insustanciales, puesto que no transgredieron en nada los principios inmovilistas del Régimen, que eran los que sostenían todo el edificio imperial de Salazar.

Hemos dicho líneas arriba que la verdadera dimensión de la guerra de Angola viene determinada por el hecho de estar compuesto por diferentes conflictos, donde las distintas luchas se solapan. Y como es normal, llegando al extremo de la lucha armada que se desarrolla en la colonia portuguesa, los conflictos menores se

36 MOREIRA, Adriano: «Política de integração», discurso del Ministro de Ultramar en la Asociação Comercial do Porto, 28 de agosto de 1961. En: Boletim Geral do Ultramar, no 434-435, agosto-septiembre de 1961. Lisboa: Agência Geral do Ultramar, p. 9. 
subordinan y se mezclan con el principal, que en este caso es el representado por el enfrentamiento del poder establecido y los movimientos de liberación en un conflicto «tipo» de descolonización, si bien es verdad que muy infiltrado por la lucha de boques. Esto implica el alineamiento de los diferentes participantes de las lizas menores con uno de los contendientes principales asociando el respeto de sus intereses o incluso la discusión de sus planteamientos políticos - más o menos acabados- a la victoria de una de las partes, en un proceso complejo de polarización que absorbe conflictos tribales, de clase, raciales, religiosos, etc. $Y$ es entonces cuando el juego salta de inmediato al terreno político sustentado por el esfuerzo militar.

A pesar de haber en cada bando pareceres más o menos distintos en determinados aspectos, proyectos más generales o más parciales y más o menos maduros, todos se reduce a priori a las alternativas de la perpetuación del dominio portugués o la independencia. Y como es lógico, dada la imposibilidad de derrotar al enemigo por la fuerza de las armas a corto o medio plazo, la lucha que se traba se centra en la ampliación de las bases de apoyo de ambos contendientes tanto en el interior como en el exterior. Los movimientos de liberación aprovechan los problemas convivenciales para atraer a las masas y a la comunidad internacional, mientras desde Lisboa se responde con las reformas que líneas arriba describíamos. Sin embargo, como clave de estas dos bóvedas alternativas para Angola y en el fondo también para el resto del Imperio Portugués- están los distintos proyectos políticos que presentan ambos, a cuyas líneas maestras se subordina el alineamiento de los otros intereses, así como la ayuda internacional.

Por tanto, no podía haber solución fuera de una victoria en el plano de las alternativas políticas que desequilibrase los apoyos sociales e internacionales hacia unos u otros, al no ser por medio de un recrudecimiento radical de la Guerra Fria que exacerbase la tensión entre los bloques, o por una derrota militar total del enemigo. La primera era una posibilidad difícil cuantificar en los análisis del orden mundial que Salazar barajaba y de los efectos que esperaba para Portugal. En cuanto a la segunda, la victoria por la fuerza resultaba no sólo prácticamente imposible, sino que además el tiempo jugaba en contra de sus posibilidades de mantener la «estabilidad militar».

A finales de 1961 estaba prevista la independencia de Tanganica, poniendo por primera vez en la frontera de Mozambique un Estado negro independiente. Dadas las tensiones internas en la Federación de Rhodesia y Niassalandia, territorio dominado por los blancos de Rhodesia del Sur hasta entonces, era de temer que evolucionase en el peor de los casos hacia la desintegración con la emergencia de dos y tres poderes independientes, previsiblemente dos de ellos negros y uno blanco, como pronto se confirmaría con el dominio negro en Niassalandia desde 1962 y sólo un año más tarde de Rhodesia del Norte, ambos opuestos al racismo blanco filo-luso de Rhodesia del Sur. Obviamente no era de esperar que la situación de acoso internacional de Portugal mejorase, y la prolongación de la lucha y de los es- 
fuerzos de vigilancia no hacían más que absorber cada vez más dinero del presupuesto del Estado, algo que no era sostenible a largo plazo. A todo ello había que unir el riesgo de que cuanto más persistía el problema angoleño, más probabilidades había de que en Guinea Bissau o Mozambique estallase la rebelión, situando entonces a Lisboa frente a una guerra de desgaste en varios frentes y sin la asistencia internacional. Por eso, dado el compromiso internacional con la descolonización, sólo cabía esperar cierta comprensión de algunos aliados y eso haciendo concesiones políticas.

Como ya hemos dicho, entre los portugueses eran prácticamente unánime al decisión de defender la unidad imperial — con la salvedad del Partido Comunista Portugués-, sin embargo no había tal consenso en cuanto al camino a seguir de cara al futuro. Parte del espectro oposicionista ya había aireado su proyecto de crear unos «Estados Unidos de Portugal», federando las colonias con la Metrópoli sobre la base de un sistema representativo y pseudo-democrático, un camino que sería igualmente tanteado por los militares del golpe del 13 de Abril, y que incluso compartía puntos en común con los pensamientos de miembros del Régimen no muy seguros de que la defensa del unitarismo nacional fuese la mejor opción, como era el caso de Marcello Caetano ${ }^{37}$. De todas maneras era entre estos diferentes pareceres dentro del Estado Novo donde estaba el juego que habría de decidir el futuro político del Imperio, y tras la derrota de los golpistas de la Abrilada la alternativa que se impuso fue la pretendidamente salomónica de Oliveira Salazar, basada en la extensión de la "autonomía administrativa», frente a las opciones federalistas de los más moderados del Régimen y del asimilacionismo de los nacionalistas ultramontanos.

Sin la menor duda, la medida más efectista en este sentido fue la equiparación legal de todas las poblaciones de las colonias extendiendo la condición de ciudadanía. El Estatudo dos Indígenas sólo afectaba a las posesiones continentales de África, es decir, a Guinea, Angola y Mozambique, el resto disfrutaba de la misma condición que los portugueses metropolitanos desde diferentes momentos. Era la pervivencia del distingo entre ciudadanos e indígenas uno de los elementos más esgrimidos a nivel internacional para demostrar que en realidad la relación existente entre Portugal y su «provincias» no era de naturaleza diferente a la de cualquier otro régimen de colonialismo, sancionando legalmente la discriminación racial en términos políticos, entre otros. Por esa razón por el Decreto-Lei 43.893 de 6 de septiembre de 1961 se abolía el Estatuto, medida que Moreira intenta disociar de las presiones internacionales.

Una de las características de ese diploma que se suprimía, a parte de privar a los nativos de los restringidos derechos ciudadanos que el Estado Novo reconocía,

37 Ver documento anónimo adjudicado a la autoría de Marcello Caetano presentado en el Consejo de Ministros de 2 de febrero de 1962, en el que se aboga por una federación entre la Metrópoli y las colonias en: TORRE GÓMEZ, Hipólito y SACHEZ CERVELLÓ, Josep: Portugal en la Edad Contemporánea (1807-2000). Historia y Documentos. Madrid, UNED Ediciones, 2000. 
conllevaba una condición de derecho privado diferencial, en tanto que los nativos regían sus relaciones por un derecho consuetudinario, mientras que los ciudadanos se sometían a la ley escrita de Portugal, regulándose los litigios entre ciudadanos y nativos por medio de reglas más o menos determinadas. En este caso, a diferencia de lo que sucedía con el distingo político, su supresión sí podía crear tensiones entre las poblaciones naturales contra Portugal, y fue por esa razón por la que se perpetuo el sistema aun habiéndose anulado la diferenciación política. Por el Decreto-Lei 43.897 se reconocía la vigencia del derecho consuetudinario, por el Decreto-Lei 43.898 se establecían los juzgados municipales encargado de dirimir los litigios entre personas sujetas a derechos diferentes; y por el Decreto-Lei 43.899 se reconocía la posibilidad de que los nativos se acogiesen voluntariamente al derecho escrito. Lo dicho no hace más que reforzar la sospecha de que para la mayor parte de la población nativa la extensión de la ciudadanía no sería una inquietud de primera magnitud, como sí la conservación de sus formas de organización, debiéndose más la reforma a motivaciones exógenas.

Dejando atrás el brillo de las alteraciones antedichas, la revisión de la administración de las colonias y de su relación con la Metrópoli era otro de los puntos fundamentales del conflicto y de ella dependería en buena medida las posibilidades de que el proyecto político de Portugal tuviese una mayor o menor aceptación interior e internacional. Sin embargo fue en este campo donde las alteraciones no se salieron ni un ápice de los límites marcados por el dogma de la unidad nacional inquebrantable del Portugal pluricontinental.

En junio de 1961 de aprobaba el Decreto-Lei 43.730, con el que se impulsaba el papel de los municipios en la administración colonial y se determinaba la dependencia de un régimen electivo de los cuerpos administrativos, con el objetivo de ampliar la participación ciudadana en este nivel de la administración local. En esa misma línea iría el Decreto-Lei 43.896 de 6 de septiembre, con el que se reorganizaban las Regedorias, instituciones administrativas al nivel de los municipios pero gestionadas por las comunidades nativas, en principio como paso previo a la constitución de juntas municipales de funcionamiento normal cuando las poblaciones diesen muestras de su preparación para ello.

El paso más importante se dio ya al final del mandato de Adriano Moreira. En septiembre de 1962 convocó la reunión del Consejo Ultramarino con el objetivo de debatir de manera colegiada sobre el futuro sistema organizativo del Ultramar, o lo que es lo mismo, la revisión de la Lei Orgánica do Ultramar Português de 1953, documento fundamental que rige la administración ultramarina y la relación de poderes en las colonias y de éstas con la Metrópoli. Para dar mayor relevancia a esta reunión también fueron convocados los miembros de los Consejos Legislativos de cada provincia, todos los gobernadores, los ex-ministros de Ultramar que seguían vivos (el único que fue invitado y no acudió fue Marcello Caetano) y representantes del Ministerio dos Negocios Estrangeiros —una muestra más de la preocupación que en Lisboa se tenía por la recepción internacional de las alteraciones. 
En su discurso de apertura de las sesiones de septiembre de 1962, el Ministro apunta de nuevo hacia la coherencia y el respeto al principio autonómico, recogido en la Constitución. Dice:

«(...) Não serve con lealdade quem, responsable a qualquer título pelo programa nacional inscrito na Constituição, usa o poder para o contrariar (...). Estamos empenhados numa tremenda luta na frente internacional, baseada em princípios conhecidos, procurando, com alguns resultados, convencer da autenticidade com que os aplicamos progresivamente [entre ellos, la descentralización administrativa y la promoción social]. Seria uma traição em plena batalha, pelo menos da parte dos respoinsáveis em qualquer grau da hierarquia do Estado, se de algum modo fossem postos en dúvida ou enfraquecidos. Mas o resultado não seria menos grave do ponto de vista da coesão da frente interna (...) no caso de poder vir a ser semeada a dúvida sobre a coerencia da própria administração»38.

El día 30 de octubre se hacía pública la resolución del Consejo Ultramarino referente a la revisión de la Lei Orgánica do Ultramar, en la que: se reafirma la unidad nacional; se rechaza la integración administrativa —esto es, la asimilación; aconseja la descentralización administrativa en todo lo que afecte a los intereses puramente provinciales; da luz verde a la coexistencia al lado de los Consejos Legislativos de tipo electivo de Consejos Corporativos; recomienda el desarrollo del municipalismo - línea por la que ya se había optado como hemos señalado; recomienda también una segunda descentralización dentro de las colonias, del poder provincial a los distritos (escalón administrativo intermedio); es favorable a la ampliación de la representación del Ultramar en la Asamblea Nacional y también en la Cámara Corporativa; apuesta por que los Gobernadores Generales hagan parte de los Consejos de Ministros en los que se traten asuntos ultramarinos; pide que haya adecuada representación de las provincias en los órganos consultivos nacionales; y reitera que los servicios nacionales dependan del Gobierno Provincial para ese ámbito y del Ministro de Ultramar para el nacional.

Este fallo no sería otra cosa que la constatación de una respuesta a las presiones internacionales por una lado, y por otro, a algunas expectativas en las colonias, si bien es verdad que en general, la población consciente, tanto blanca como de color, estaban en unos presupuestos que habían superado hacía tiempo el autonomismo administrativo restringido que se pregonaba. Únicamente donde la revisión estatutaria podía ir más allá era en Cabo Verde, sobre cuya vinculación a la Metrópoli se estaba trabajando con el objetivo de la instauración de una «adyacencia tendencial» o lo que es los mismo, un régimen especial próximo al de los archipiélagos de Azores y Madeira, orientado a una mayor integración en la Metrópoli.

38 Discurso del Ministro Adriano Moreira dando apertura a la reunión del Consejo Ultramarino, 22 de septiembre de 1962. En: Boletim Geral do Ultramar, no 448, octubre de 1962. Lisboa: Agência Geral Do Ultramar, p. 27. 
El ejecutor de las reformas fue depuesto de su cargo en la remodelación ministerial de 4 de diciembre de 1962, siendo además destituido con él su equipo: los Subsecretarios de Estado de Fomento, Costa Freitas, y de Administración Ultramarina, Moreira Rato, y poco tiempo después uno de los hombres próximos, el Gobernador General de Mozambique, Sarmento Rodrígues. Al cargo de Ministro retornaban los militares de la mano del comandante Peixoto Correia. Por esa razón, la nueva Lei Orgânica do Ultramar Portugués fue aprobada ya bajo la gestión del nuevo Ministro de Ultramar en 1963.

Si hacemos caso a lo que Adriano Moreira nos dice acerca de su destitución, la raíz habría que buscarla en un cambio en el equilibrio de fuerzas en la lucha interna desatada a lo largo de 1962 por esa reforma de la ley fundamental de la administración ultramarina, al reforzarse el grupo de los integracionistas frente a los partidarios de una autonomía progresiva e irreversible. La diferencia radicaba en que los autonomistas abogaban por una transferencia de las competencias vertical, del Ministerio de Ultramar a los Gobiernos Provinciales, mientras que los integracionistas defendían una transferencia de competencias horizontal, desde el Ministerio de Ultramar al resto de los ministerios, de modo que los poderes de éstos se extendiesen a las colonias. Para mucho — según el ex-ministro siempre por intereses privados - la propuesta de descentralizar sería una ofensa inadmisible ${ }^{39}$.

A pesar de todos los esfuerzos, la mayor parte de los gobiernos aliados occidentales, en los que se estaba pensando a la hora de acometer los cambios, recibieron con total frialdad las reformas portuguesas. A esas alturas para todos quedaba claro que la única salida admisible para Portugal era el reconocimiento del derecho de autodeterminación de los pueblos colonizados y la realización de una consulta donde la independencia total estuviese entre las opciones, bajo la supervisión internacional, con una plazo de ejecución más o menos dilatado según los casos, y con miras a preservar los lazos de unión a los que las partes estuviesen dispuestas ${ }^{40}$. Muy al contrario de esto, el afán de Lisboa siguió siendo el inmovilismo y la resistencia a ultranza, tal vez aguardando a esa alteración en el orden internacional de grandes dimensiones que obligase a Occidente a reconsiderar su posición de cara a las aspiraciones de Portugal.

\footnotetext{
39 MOREIRA, Adriano: «Os trasmontanos no mundo: Luaciano Cordeiro e Sarmento Rodríguez». En: Comentarios. Lisboa: Academia Internacional da cultura portuguesa, 1989, pp. 101 y 102.

40 Ver: AIRES OLIVEIRA, Pedro: Os Despojos da Aliança. Lisboa, Tinta da China Edições, 2007, pp. 258-263.
} 


\section{FUENTES}

\section{Documentales}

Arquivo Oliveira Salazar (AOS)

Arquivo Histórico Ultramarino (AHU)

\section{Hemerográficas}

Anuario Estatístico do Ultramar.

Boletim Geral do Ultramar, Lisboa: Agência Geral do Ultramar.

Diário do Governo, 1a Serie.

Nova Legislação Ultramarina.

Orçamento do Estado.

Orçamento Geral de Mozambique.

Orçamento Geral de Angola.

Ultramar. Revista da comunidade portuguesa e da atualidade ultramarina internacional.

Lisboa: Comissariado Nacional da Mocidade Portuguesa.

\section{Otros recursos documentales}

Carta de las Naciones Unidas: http://www.un.org/spanish/aboutun/charter/index.htm Centro de Documentación de la ONU: http://www.un.org/spanish/documents/

Debates Parlamentares. Catálogos Generais: http://debates.parlamento.pt/?pid=r2

Diario da República. http://dre.pt/

\section{Bibliografía}

Aires Oliveira, Pedro: Os Despojos da Aliança. Lisboa, Tinta da China Edições, 2007.

Alexandre, Valentim: Velho Brasil, novas Áfricas. Portugal e o Imperio (1808-1975). Biblioteca das Ciencias do Homem, Edições Afrontamento, Porto, 2000.

AmoRim, Fernando Pacheco de: Da Lei Orgánica do Ultramar. Considerações a cerca da proposta de lei para sua revisão e do parecer da Câmara Corporativa. Coimbra, 1963.

AMORIM, Fernando Pacheco de: Três caminhos da política ultramarina. Coimbra, 1962.

CAstaño, David: Paternalismo e Cumplicidade: As relações Luso-Britânicas de 1943 a 1949. Lisboa, Colecção Prémio Teixeira de Sampaio-Associação dos Amigos do Arquivo Histórico Diplomático, 2006.

CAstelo, Caudia Orvalho: Passagens para a África portuguesa: o povoamento de Angola e Moçambique com naturais da metrópole (1920-1974). Oporto: Edições Afrontamento, 2007.

Chamberlain, M. E.: La descolonización. La caída de los imperios europeos. Barcelona: Ariel Historia, 1997. 
Clarence-Smith, Gervase: O III Imperio Português 1825-1975. Trad. de María João Pinto. Lisboa: Teorema, 1990.

Cunha Leal, F. P.: A Patria em perigo. Coisas do tempo presente. Lisboa, 1962.

FonseCA, Ana Mónica: A Força das Armas: O Apoio da República Federal da Alemanha ao Estado Novo (1958-1968). Instituto Diplomático, Colecção Biblioteca Diplomática, Serie D, Número 7, Ministerio dos Negocios Estrangeiros, 2007.

Fortunato ArRifes, Marco Paulo: «As políticas coloniais de defensa de Angola (19261960). Um poder militar autista». Historia, no 20, (diciembre de 1999), pp. 38-47.

Franco NogueIRA, Alberto: Salazar. A resistencia (1958-1964), Vol.V. Oporto: Civilização, 2000.

GrIMAL, Henri: Historia de las descolonizaciones del siglo XX. Madrid: IEPALA Editorial, 1989. Homem de Melo, Manuel José: Portugal o Ultramar e o futuro. Lisboa, 1962.

Jiménez Redondo, J. C.: Franco e Salazar: as relações luso-espanholas durante a Guerra Fría (1930-55). Lisboa, Assirio e Alvim, 1996

Jiménez Redondo, J. C.: Pervivencia y superación del Iberismo: los nuevos condicionantes de la política peninsular (1939-55). Madrid, Servicio de Publicaciones de la Universidad Complutense de Madrid, 1992.

KI-ZeRBo, Joseph: Historia del África Negra. Del siglo XIX a la época actual. Madrid: Alianza Editorial., 1980, vol. II.

MARTINS, Fernando: «A política externa do Estado Novo, o Ultramar e a ONU: Uma doutrina histórico-jurídica (1955-1968)». Penélope, no 18, 1997, pp. 189-206.

MoREIRA, Adriano: «Os trasmontanos no mundo: Luaciano Cordeiro e Sarmento Rodríguez». En: Comentarios. Lisboa: Academia Internacional da cultura portuguesa, 1989. MoreIRA, Adriano: «Portugal e o Artigo 73 da Carta das Nações Unidas». Lisboa, 1957.

Nuno Rodrígues, Luís: «A Administração Johnson e a Questão Colonial Portuguesa: 0 Plano Anderson». En: Nuno Rodrígues, Luís (Coord.): Regímenes e Imperio: As Relações Luso-Americanas no Século XX. Lisboa, IPRT, 2006, pp. 90-93.

Rodrigues QueIROS, Afonso: «Portugal e a descolonização». Conferencia pronunciada en la Facultad de Letras de la Universidad de Coimbra en 1 de diciembre de 1961. Coimbra, 1961.

Rosas, Fernando (coord.): «Historia de Portugal: O Estado Novo». En: MATosso, José (dir.): Historia de Portugal, 8 vols. Círculo de Leitores, 1994, vol. 7.

SÁnChez Cervelló, J.: El último imperio occidental: la descolonización portuguesa (19741975). Cuadernos de Estudios Luso-Españoles, № 2. Mérida, UNED, 1998.

SIlva Costa Marcos, Daniel da: Salazar e De Gaulle: A França e a Questão Colonial Portuguesa 1958-1968). Instituto Diplomático, Colecção Biblioteca Diplomática, Serie D, Número 8, Ministerio dos Negocios Estrangeiros, 2007.

Telo, Antonio: «Portugal, Os Estados Unidos e a NATO». En: Nuno RodríGues, Luís (Coord.): Regímenes e Imperio: As Relações Luso-Americanas no Século XX. Lisboa, IPRT, 2006, pp. 45-86.

Telo, Antonio: Economía e Imperio no Portugal Contemporâneo. Lisboa, Edições Cosmos, 1994.

Telo, Antonio y Torre Gómez, Hipólito: Portugal y España en los sistemas internacionales contemporáneos. Mérida, Junta de Extremadura, 2003 
Torre Gómez, Hipólito y Sachez Cervelló, Josep: Portugal en la Edad Contemporánea (1807-2000). Historia y Documentos. Madrid, UNED Ediciones, 2000.

TORRE GómEZ, Hipólito: «Las colonias portuguesas en la política internacional». En TORRE GómeZ, Hipólito de la: Portugal, España y África en los últimos cien años. IV Jornadas de estudios Luso-Españoles. UNED, Mérida, 1992.

TORRE GómeZ, Hipólito: Portugal en el exterior. Madrid: UNED, 2006. 
